S1 File- Partial regression Plots between Musculoskeletal Symptoms (MSSs) and Average daily time of computer use and Mental Work Load (MWL) Factor

\title{
Women's Group
}

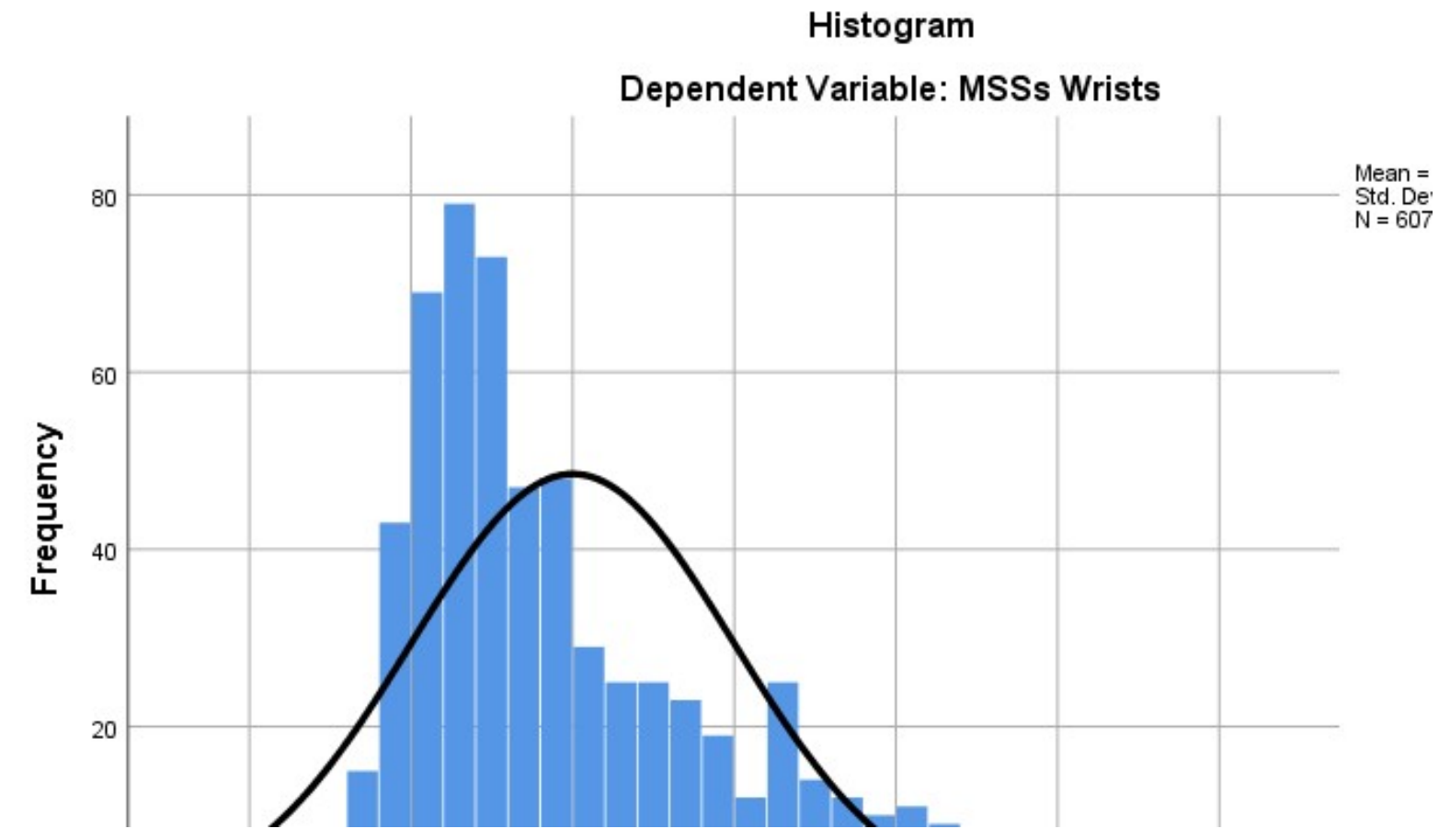

Normal P-P Plot of Regression Standardized Residual

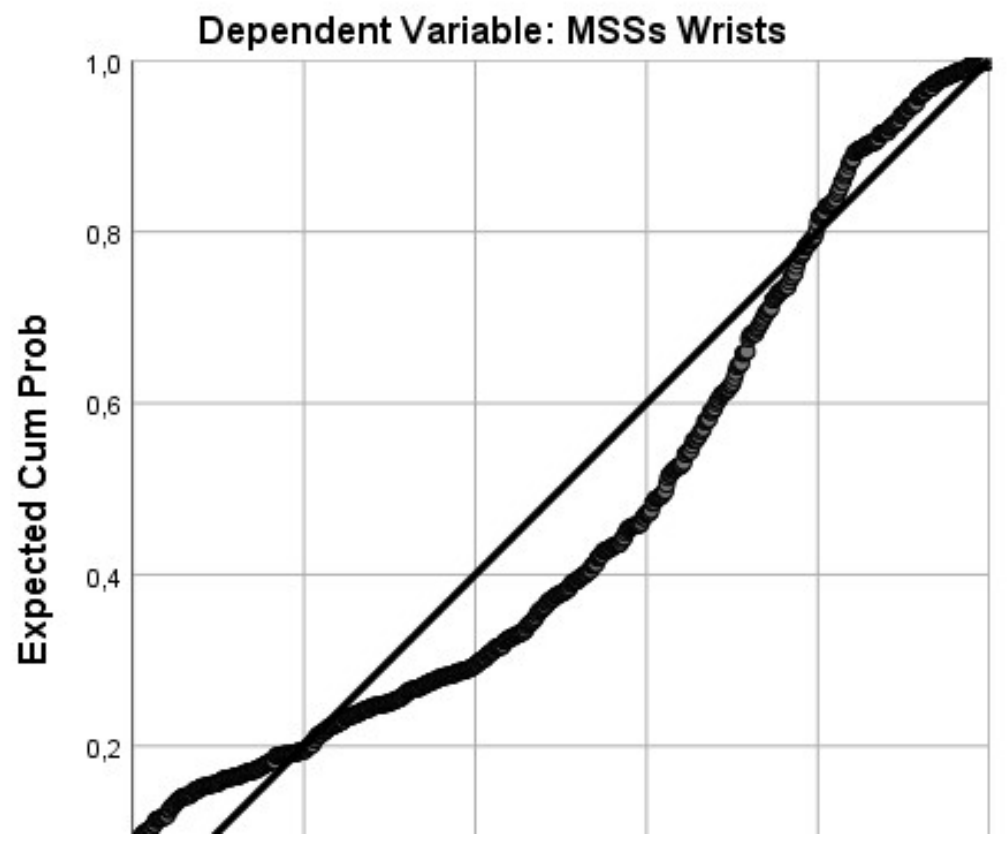


Partial Regression Plot

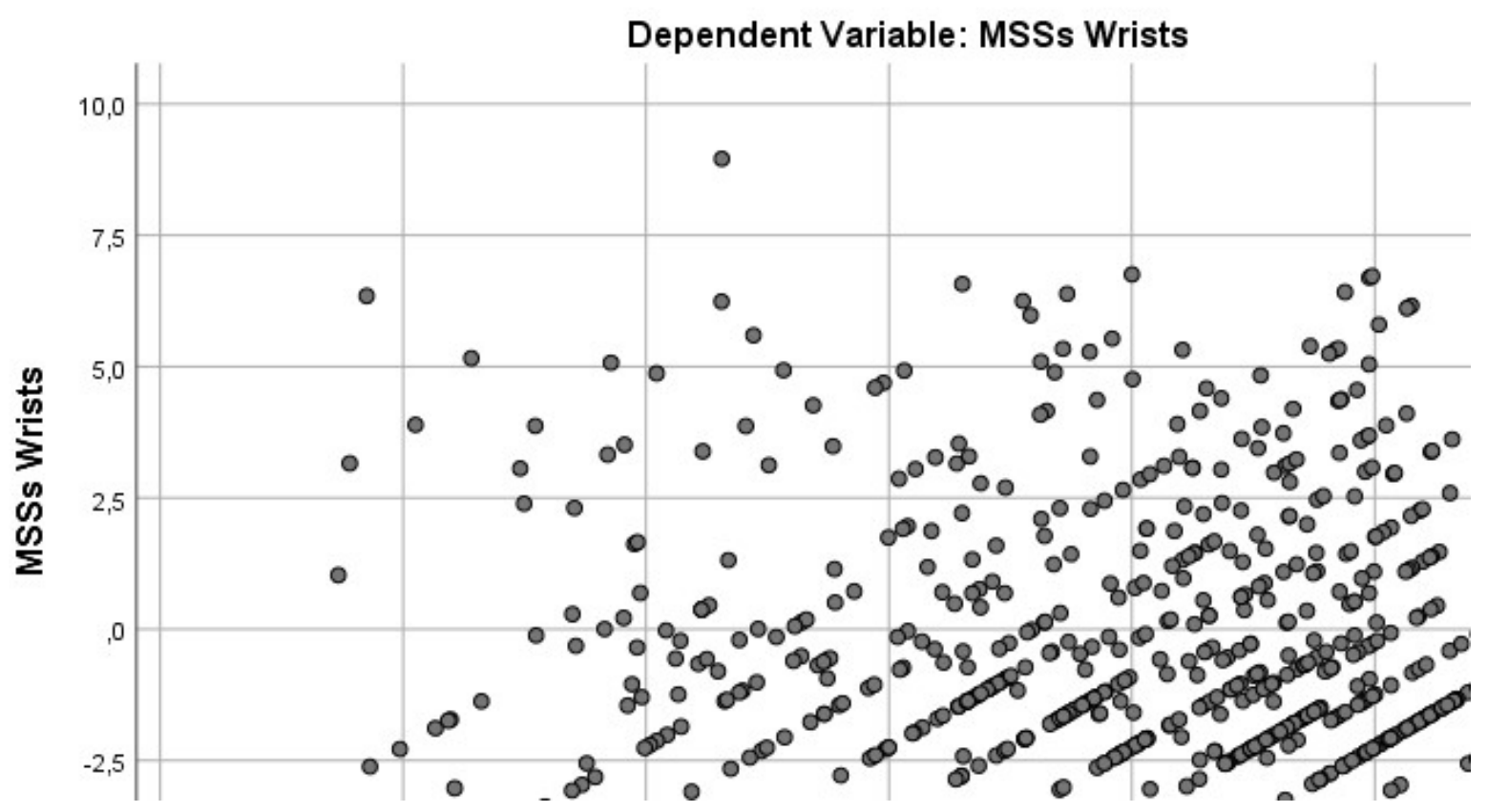

Partial Regression Plot

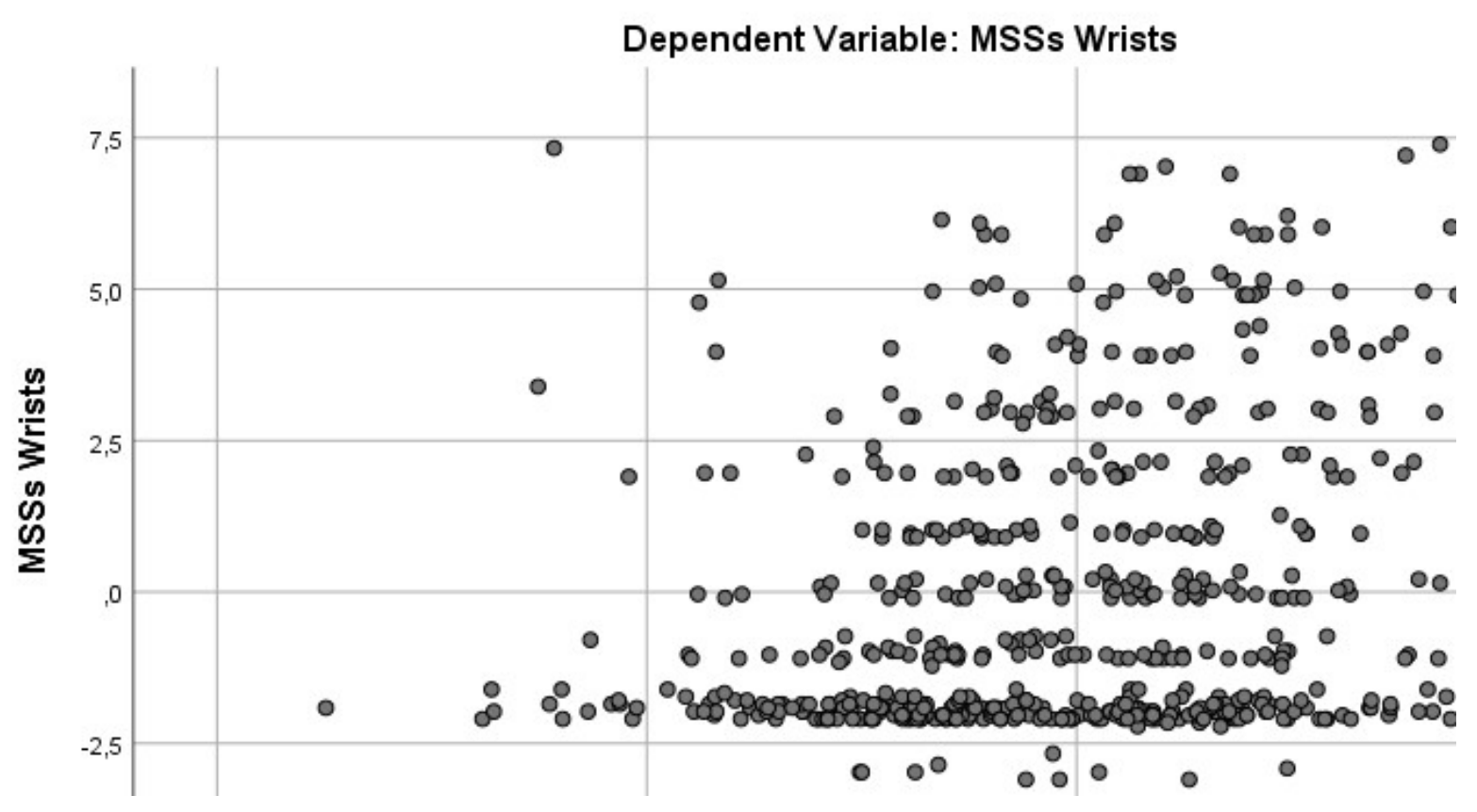


Histogram

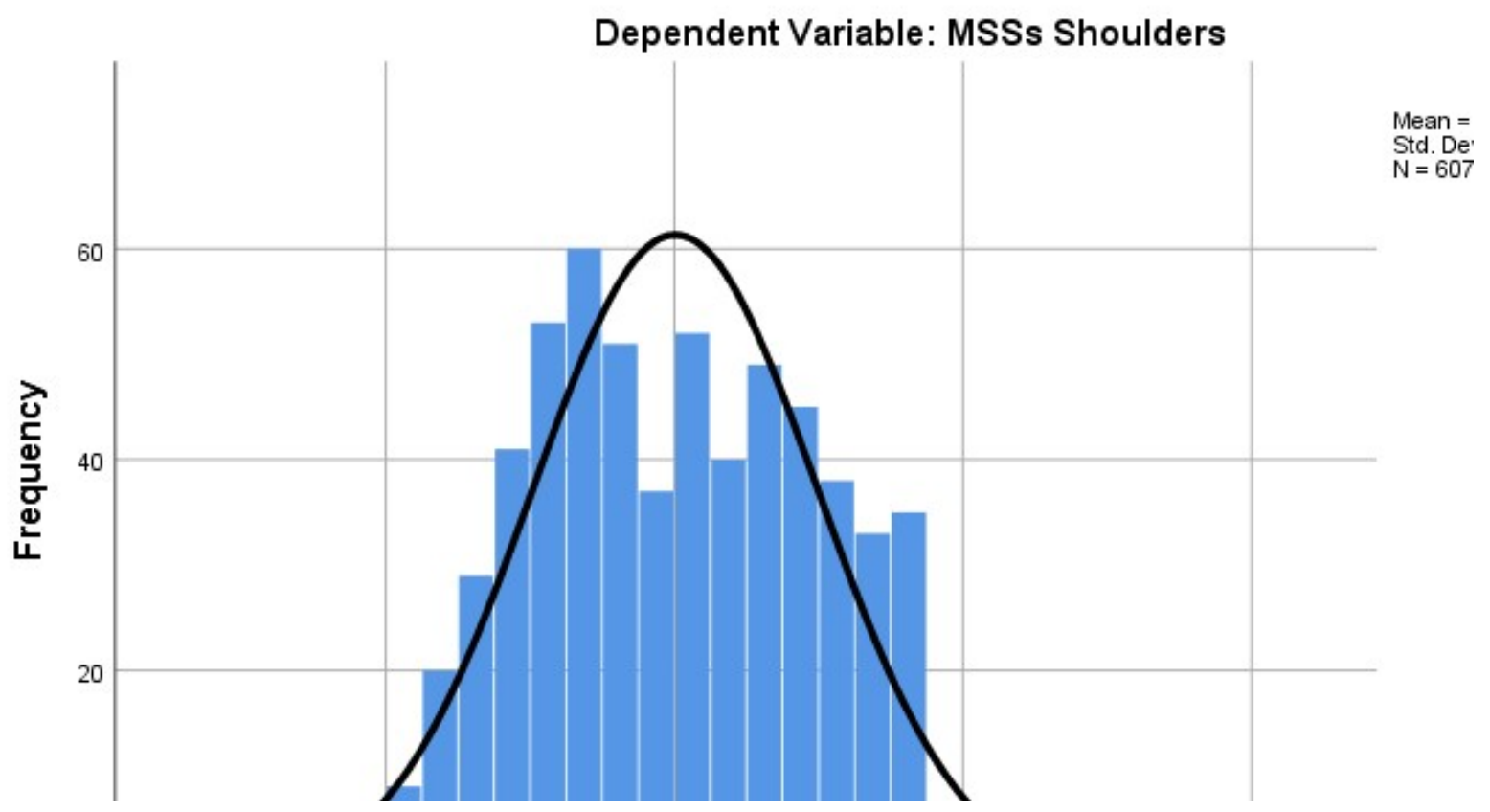

Normal P-P Plot of Regression Standardized Residual

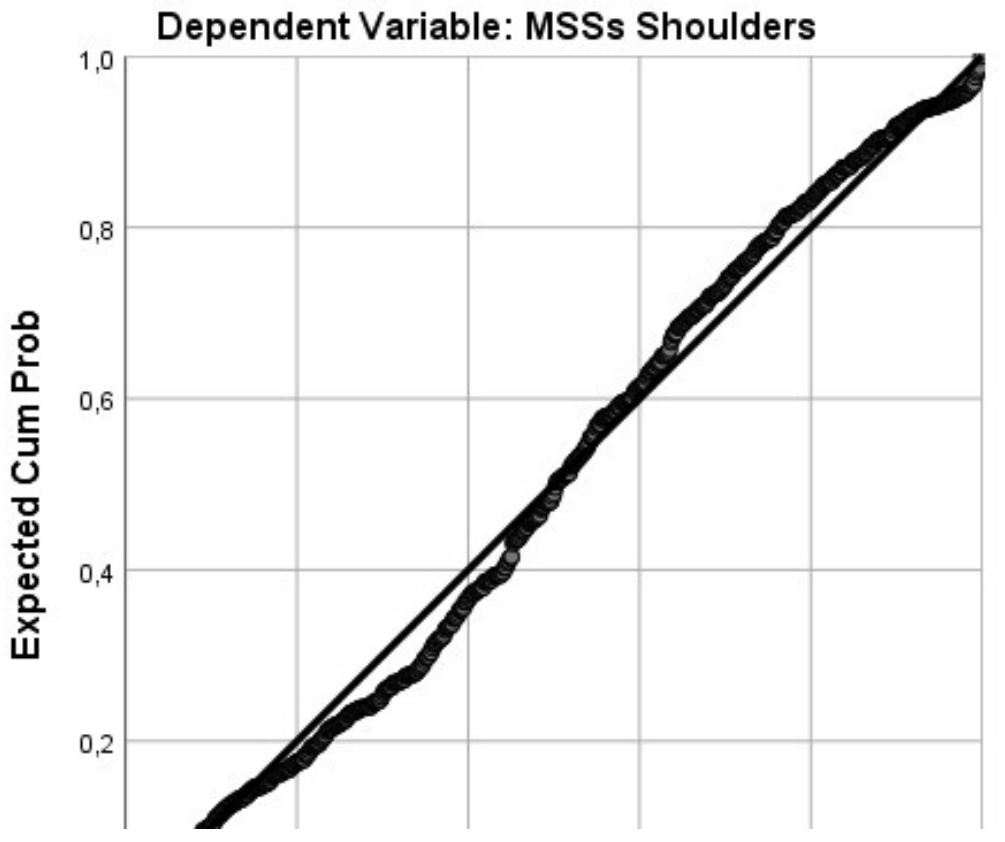


Partial Regression Plot

Dependent Variable: MSSs Shoulders

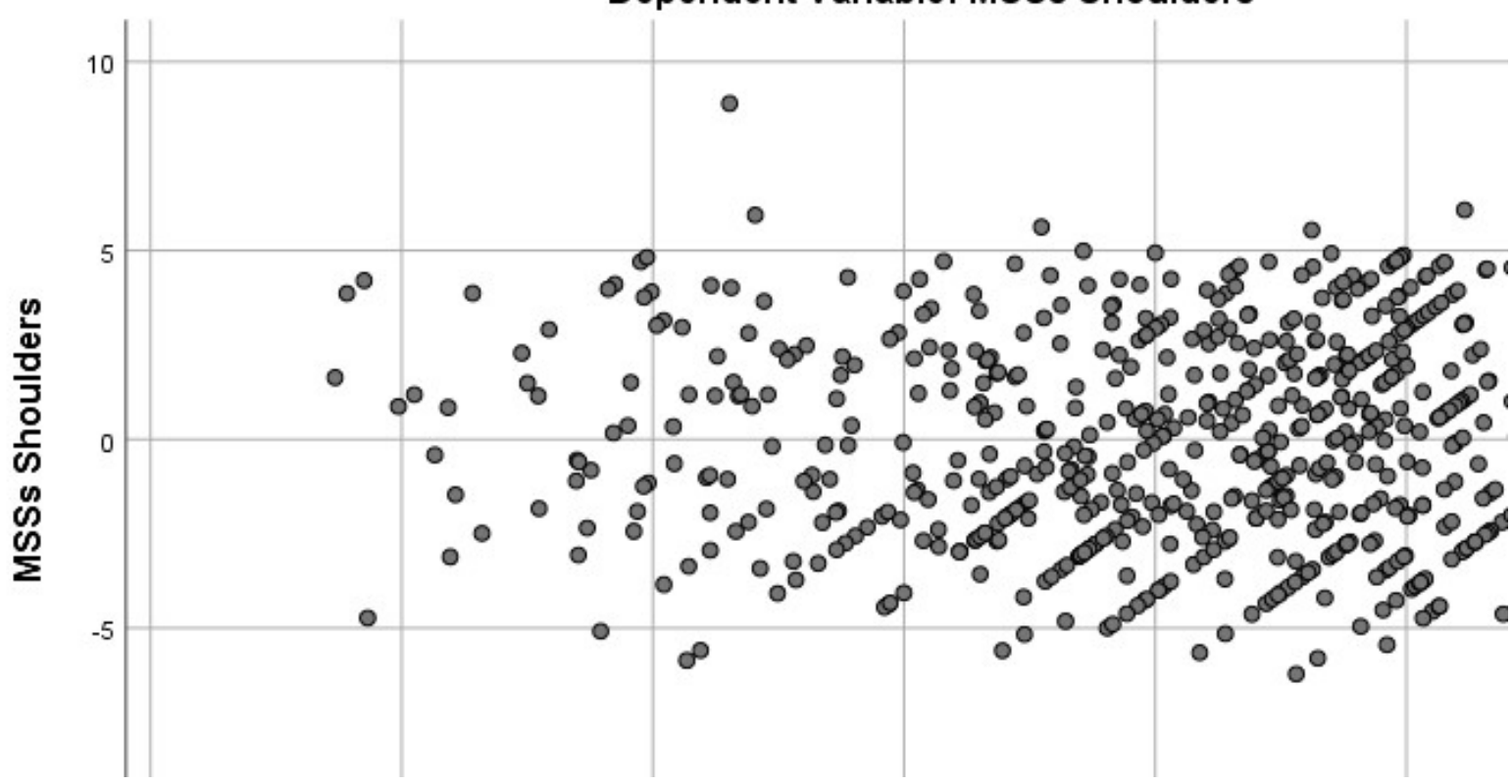

Partial Regression Plot

Dependent Variable: MSSs Shoulders

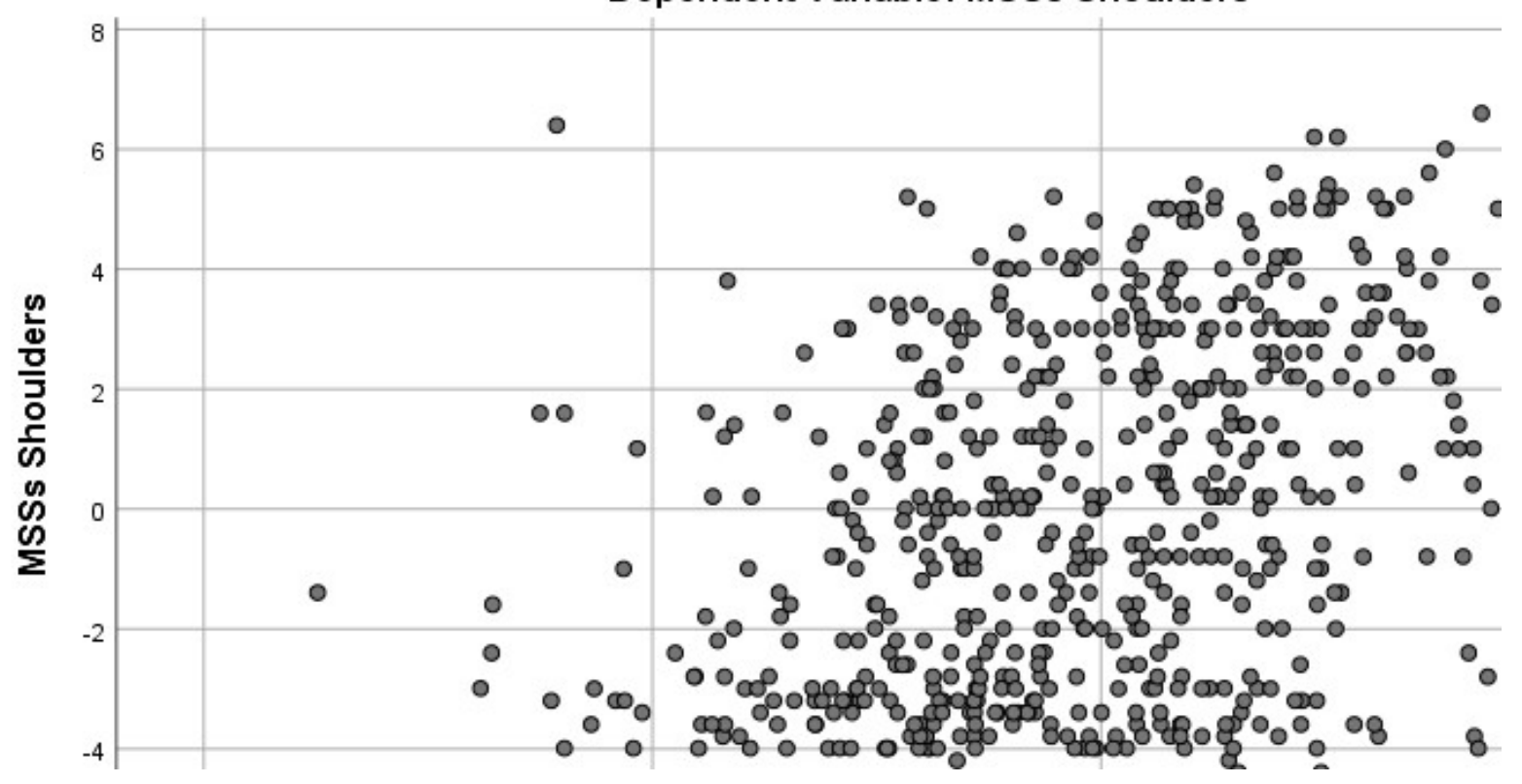




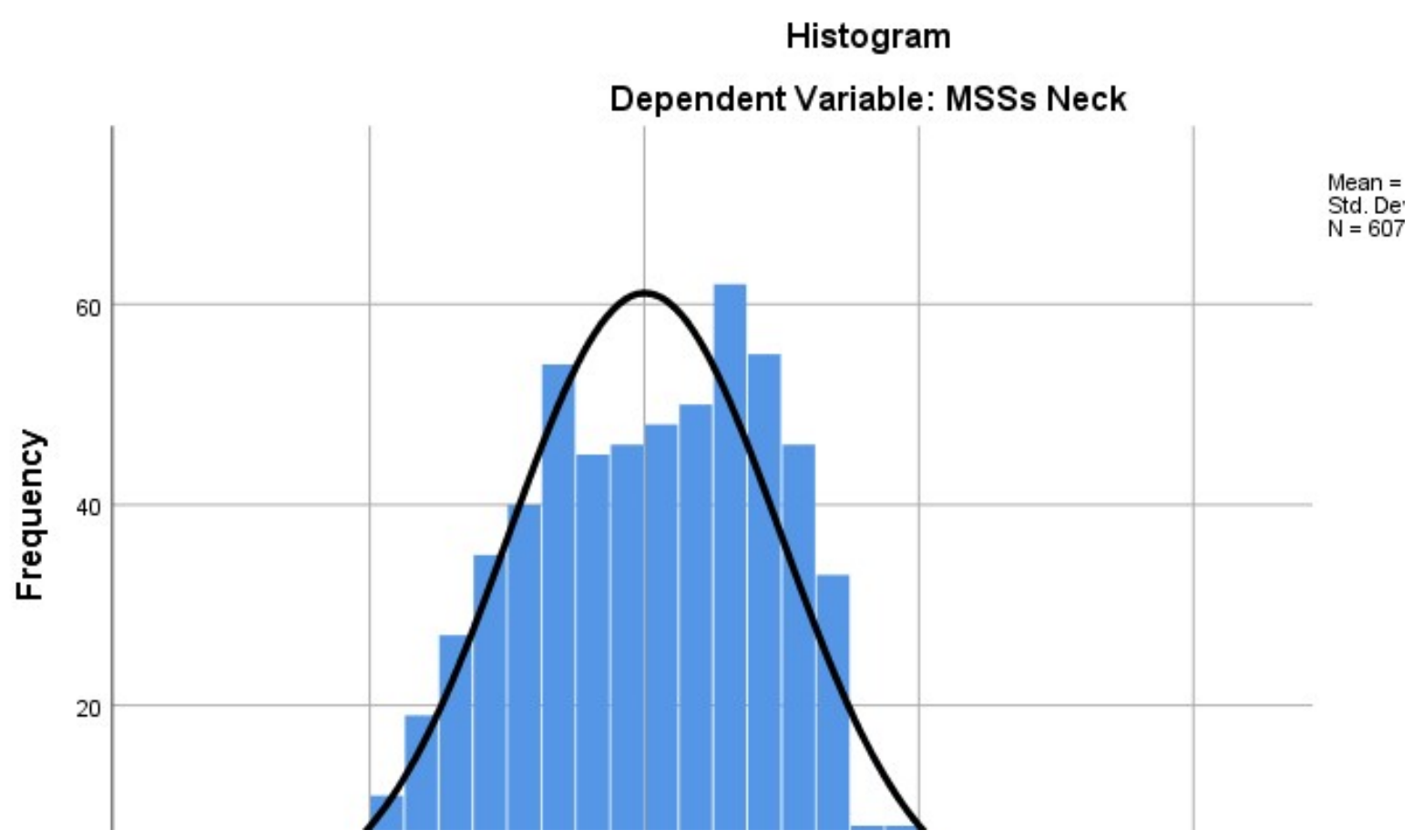

Normal P-P Plot of Regression Standardized Residual

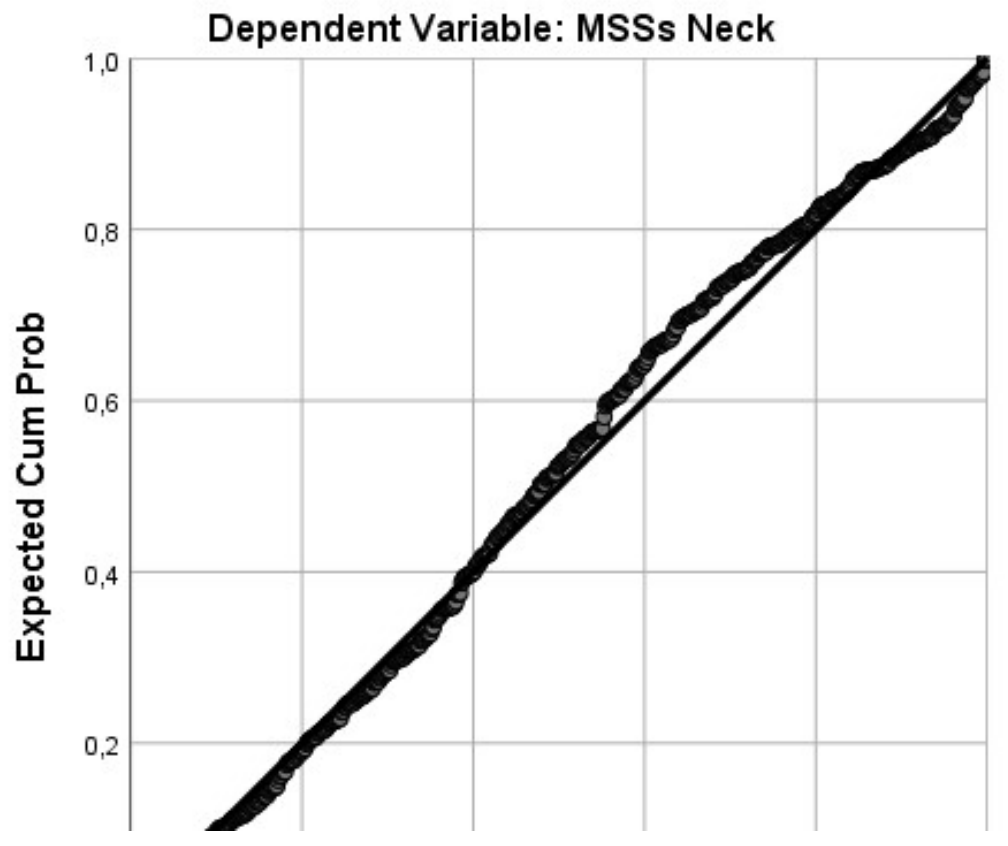


Partial Regression Plot

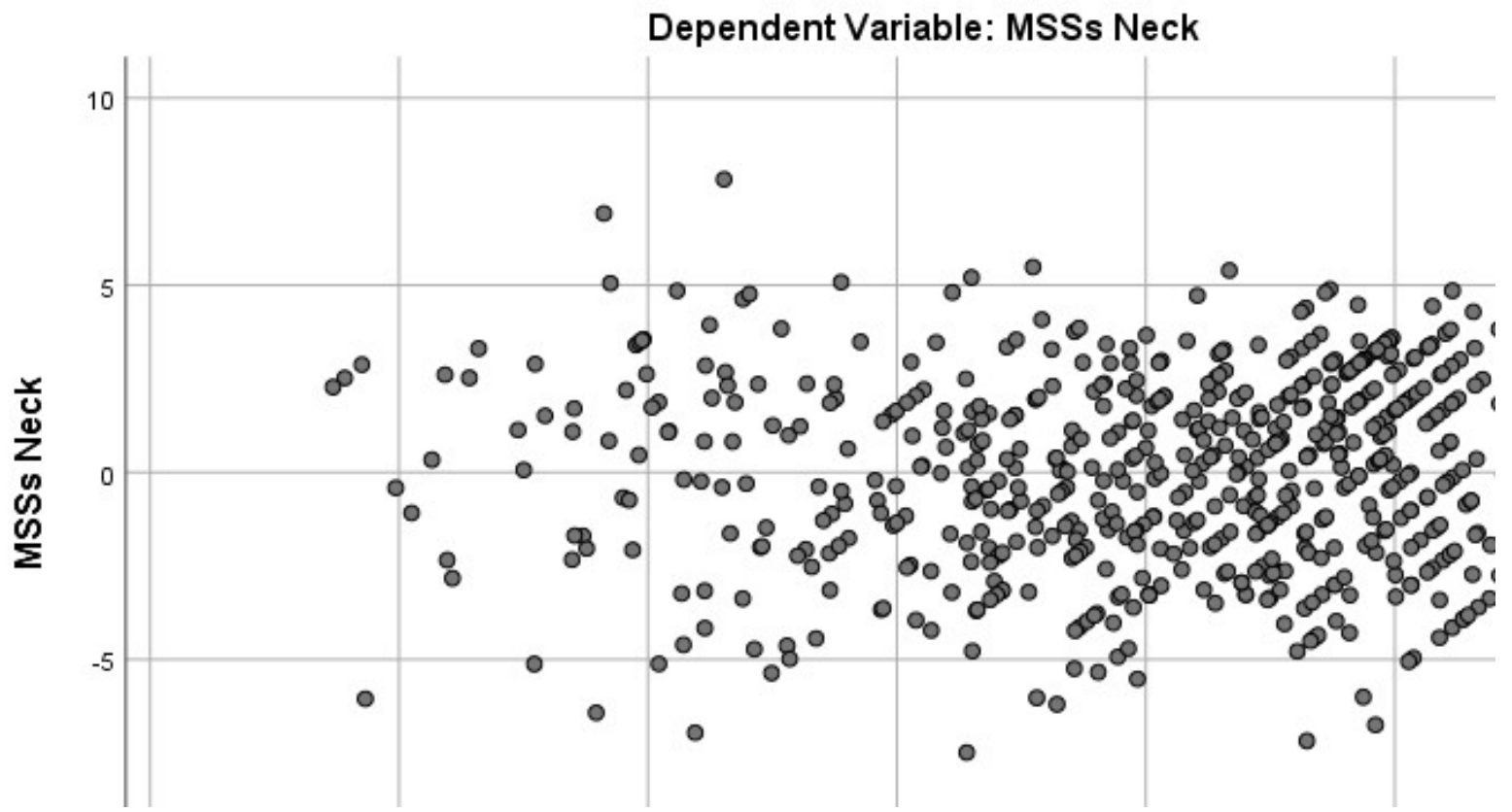

Partial Regression Plot

Dependent Variable: MSSs Neck

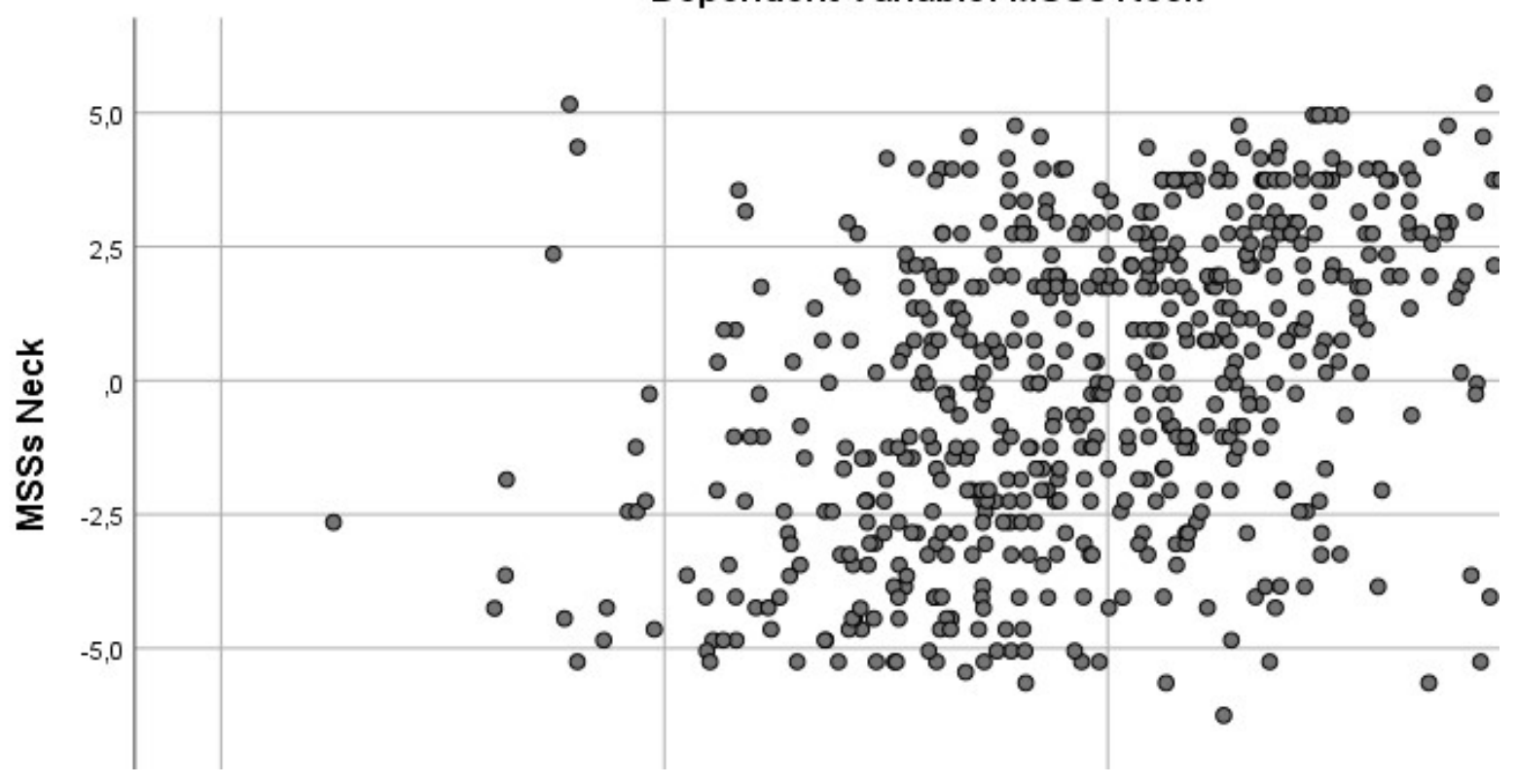




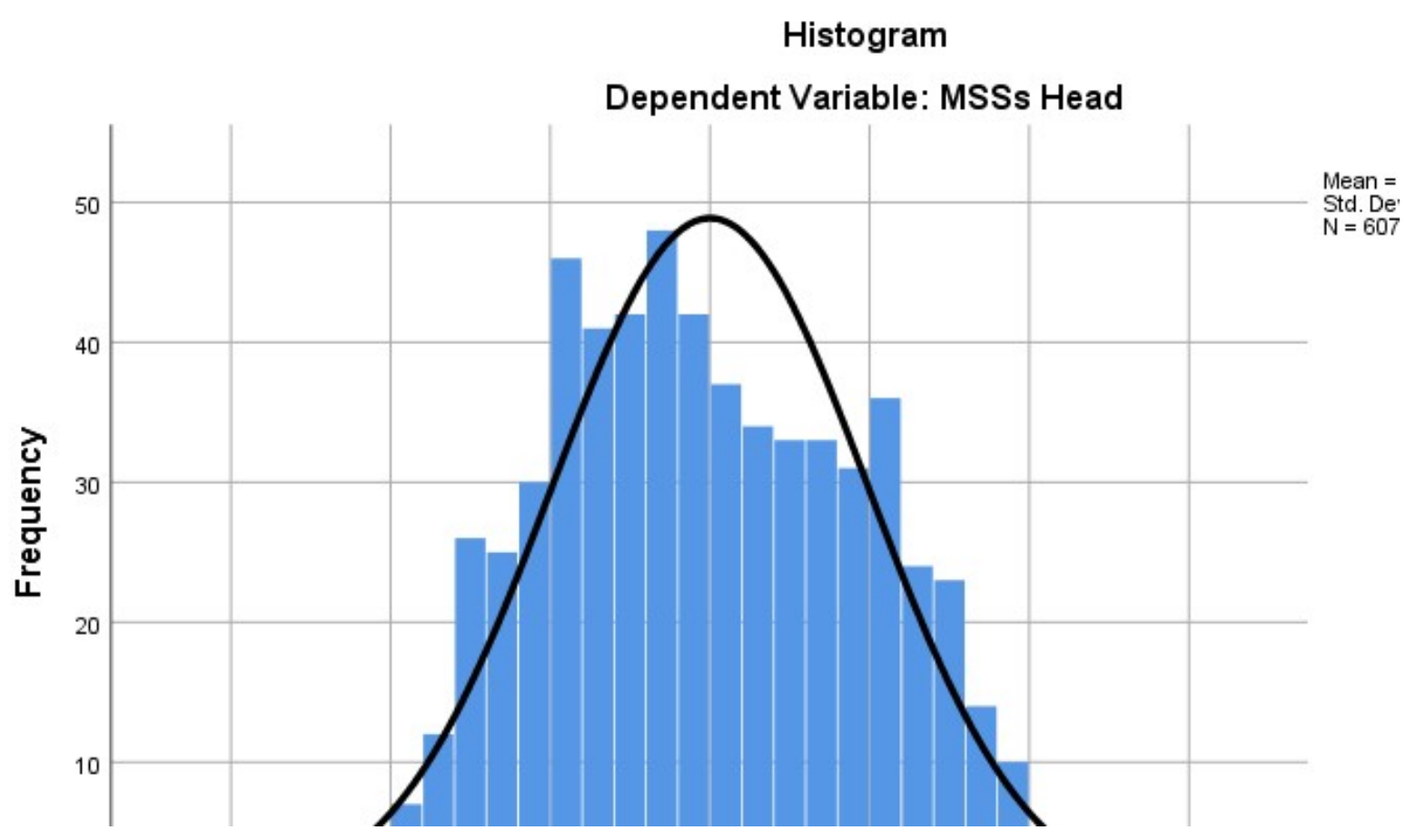

Normal P-P Plot of Regression Standardized Residual

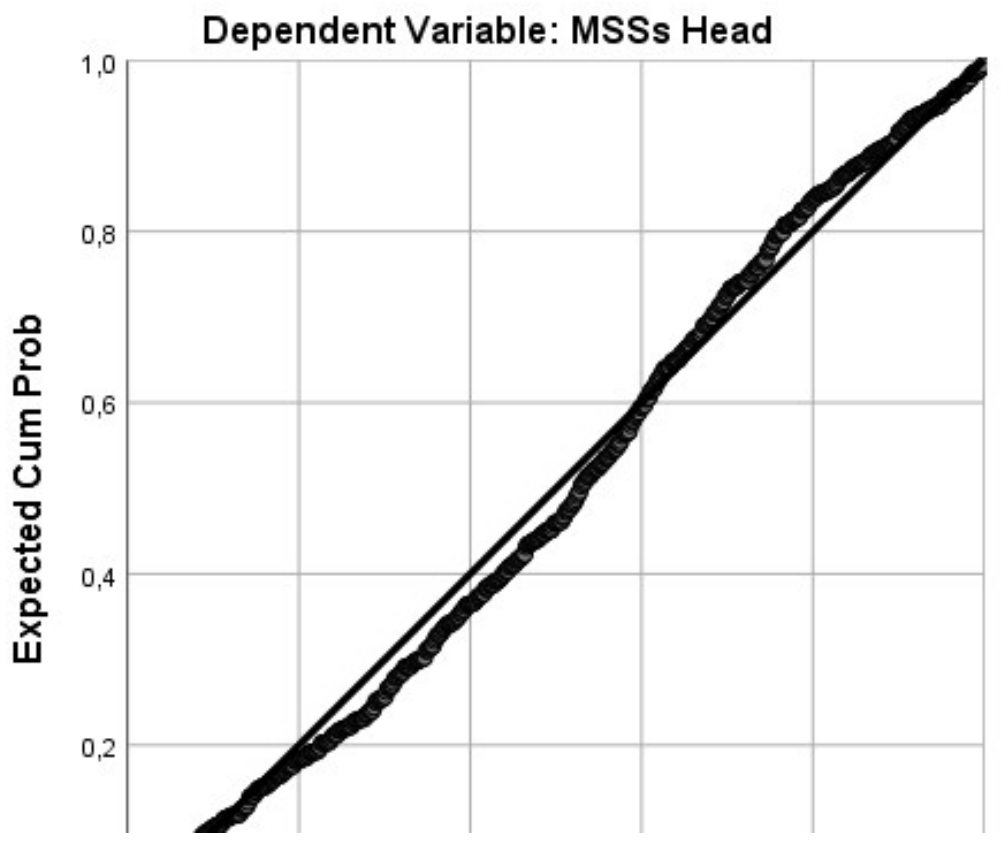


Partial Regression Plot

Dependent Variable: MSSs Head

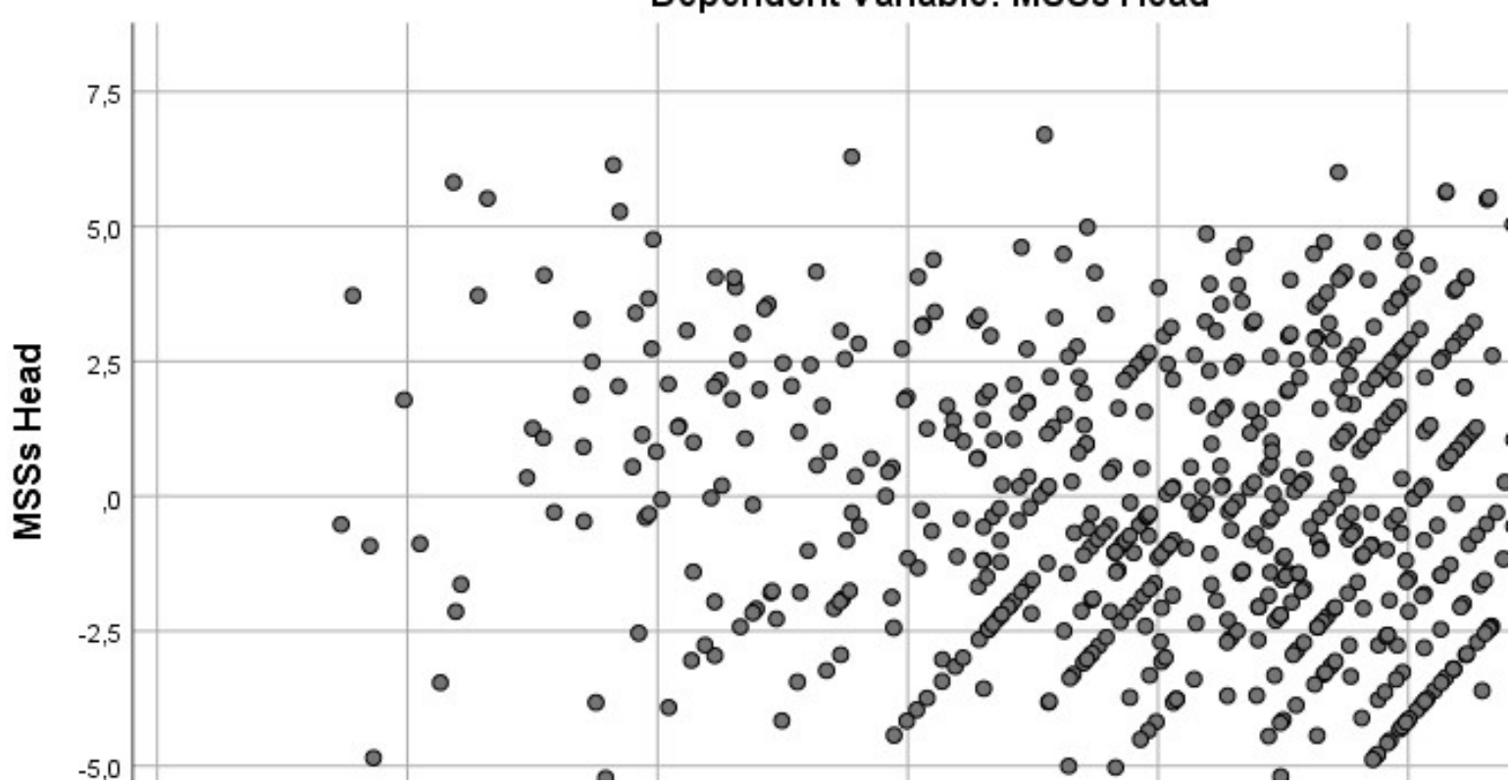

Partial Regression Plot

Dependent Variable: MSSs Head

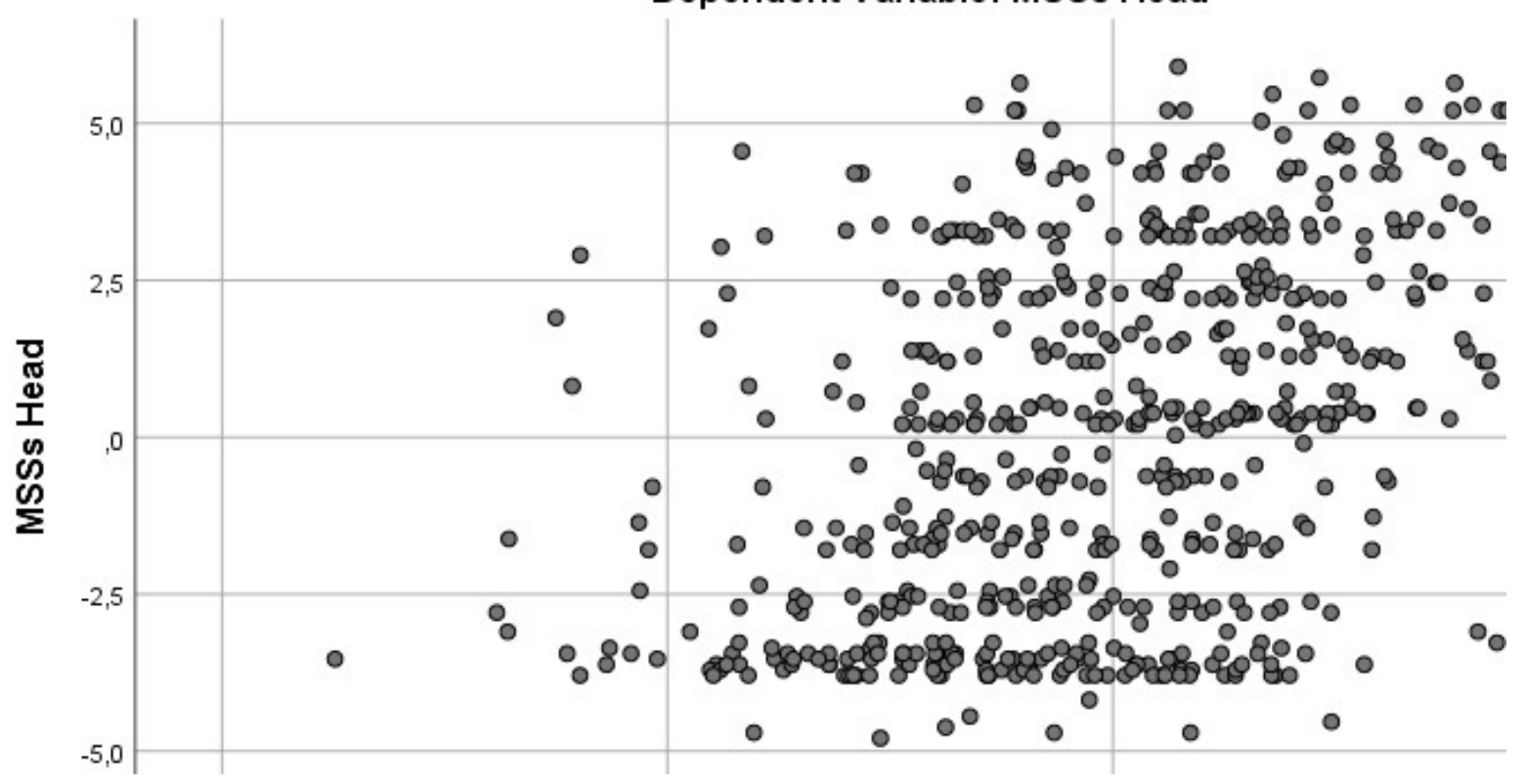




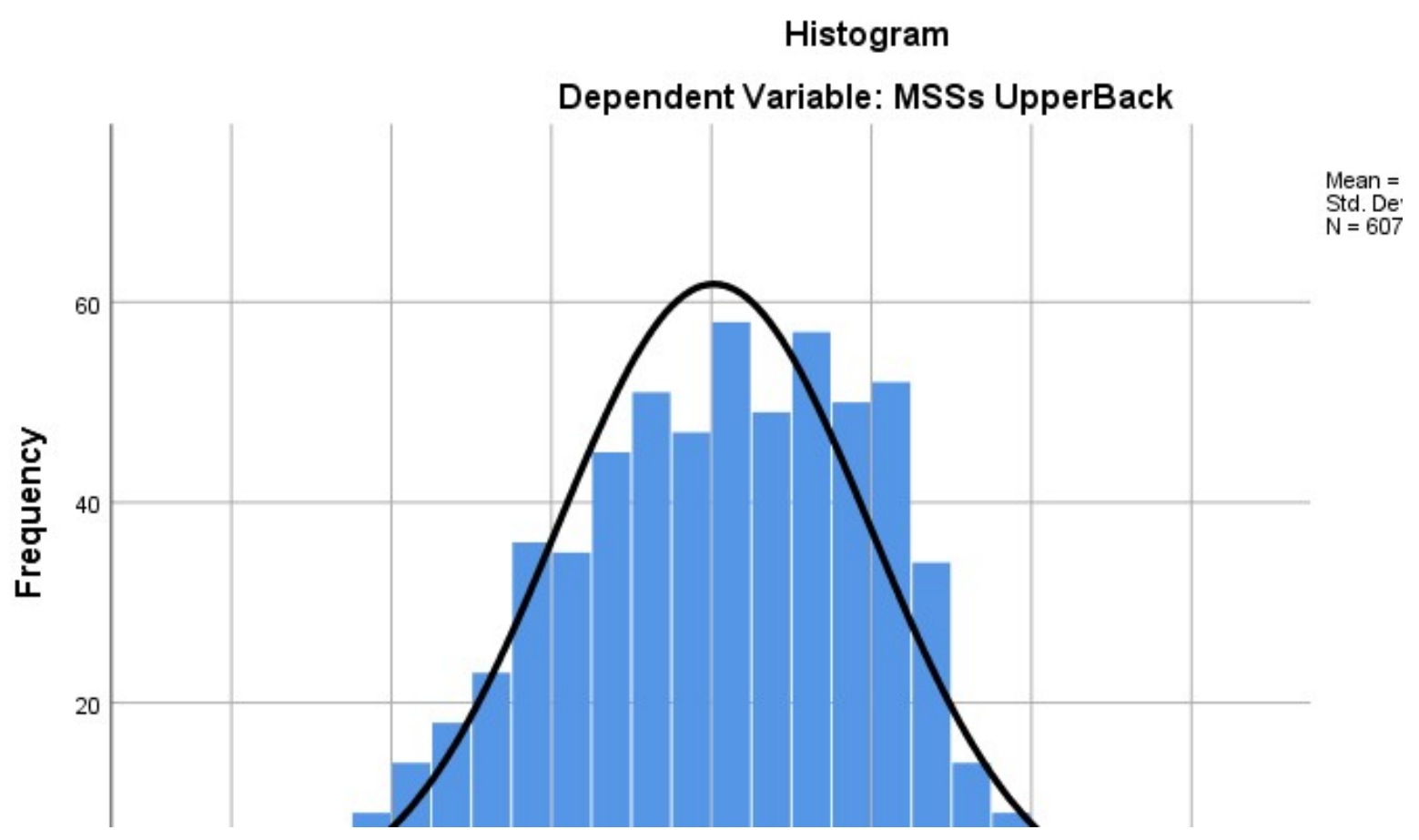

Normal P-P Plot of Regression Standardized Residual

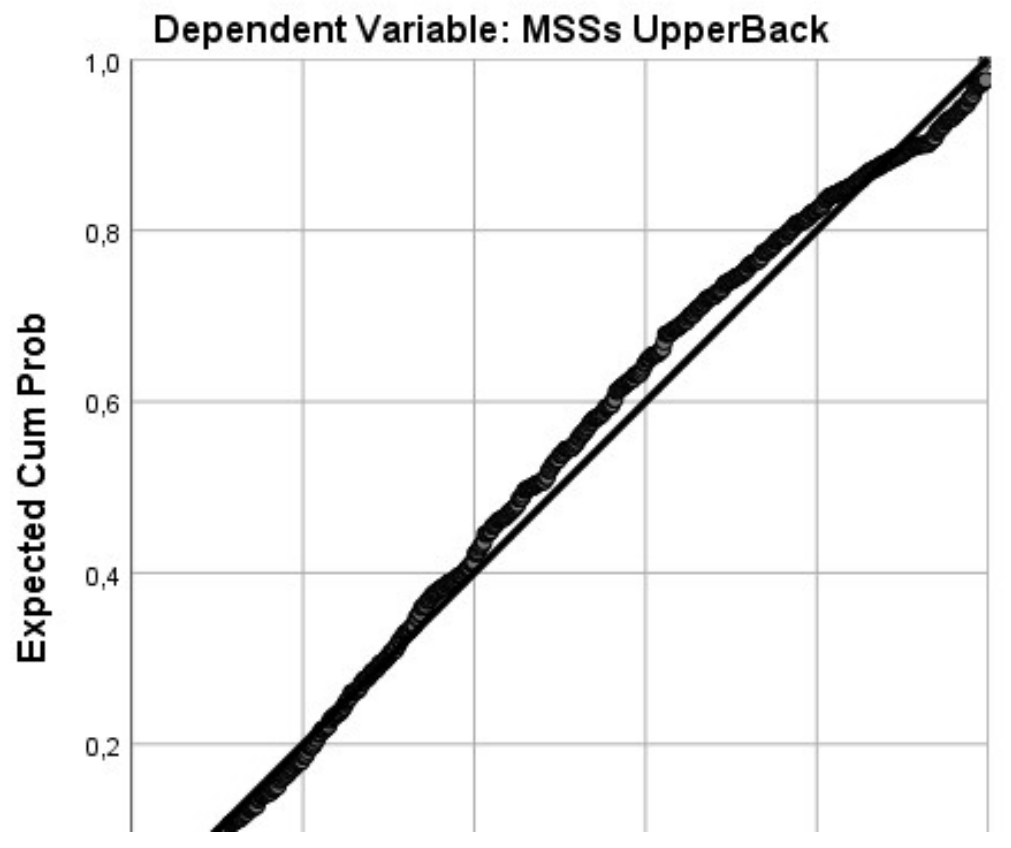


Partial Regression Plot

Dependent Variable: MSSs UpperBack

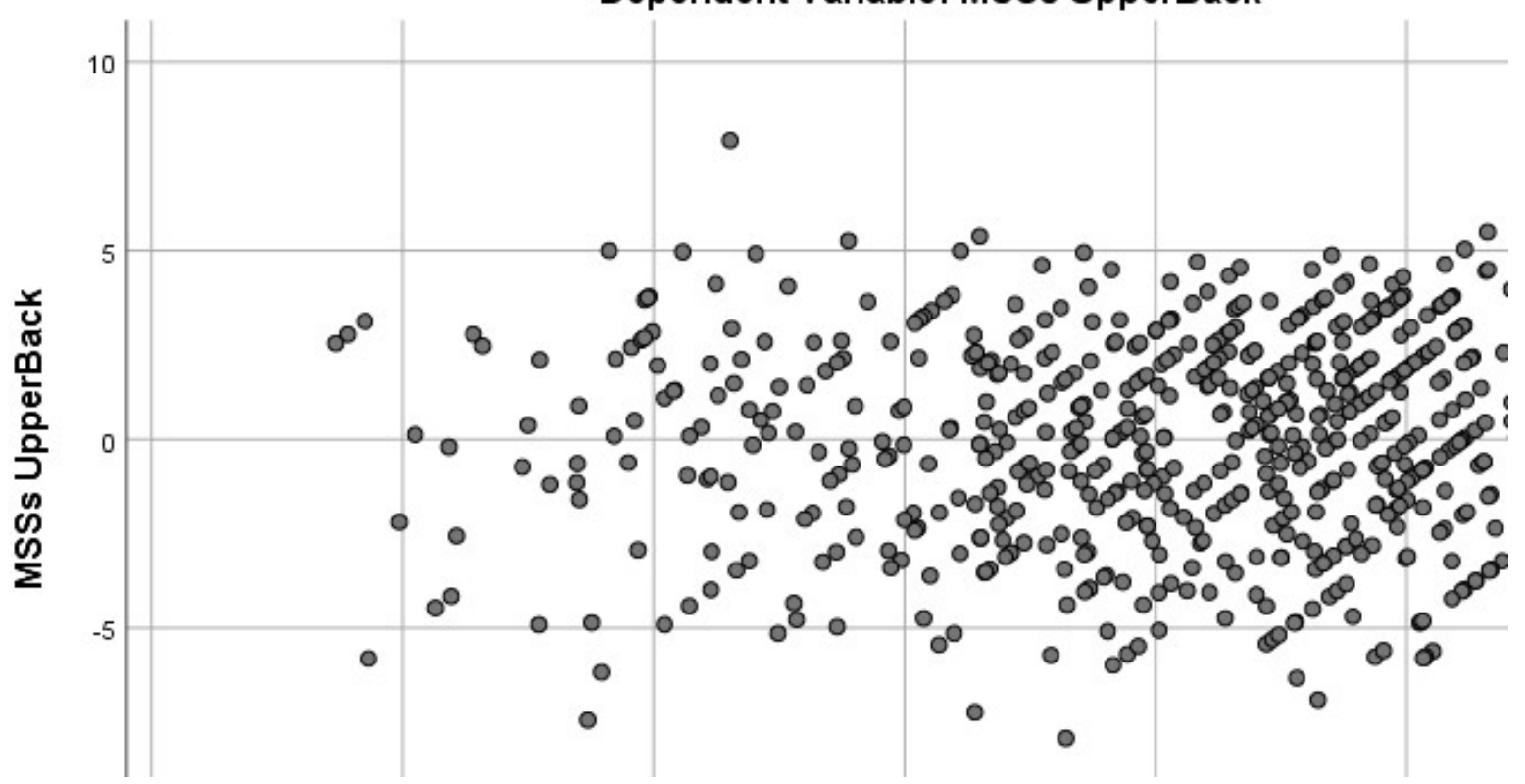

Partial Regression Plot

Dependent Variable: MSSs UpperBack

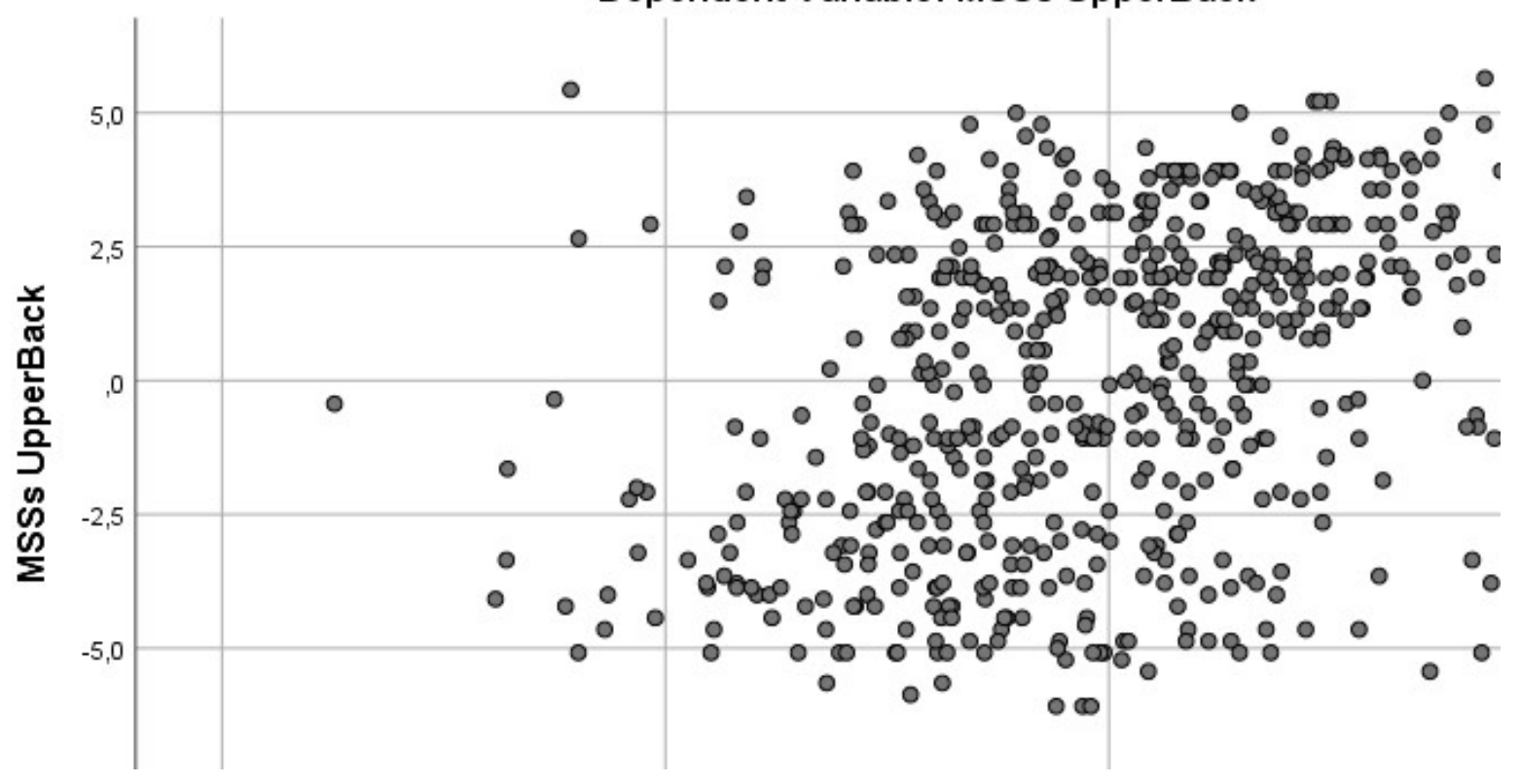




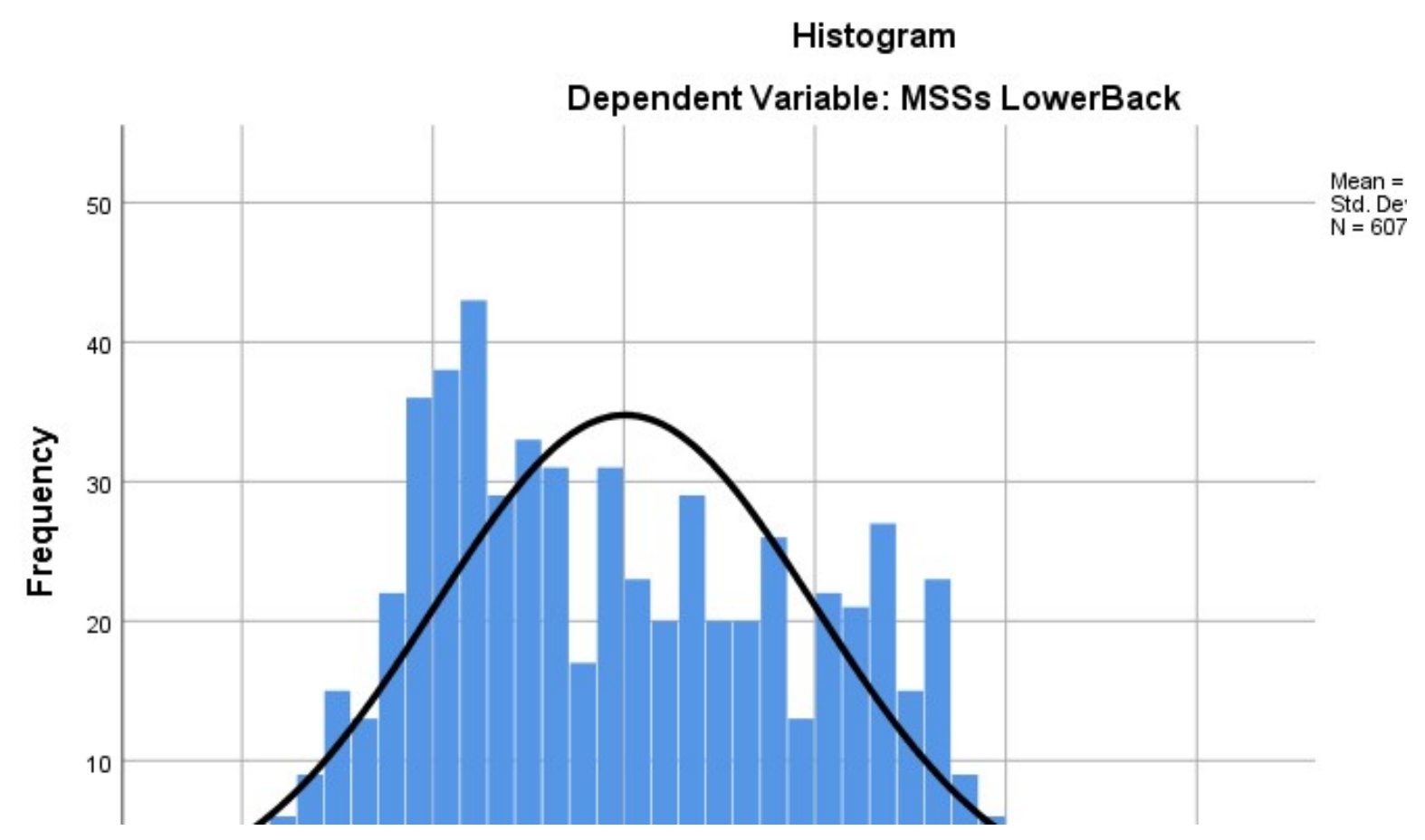

Normal P-P Plot of Regression Standardized Residual

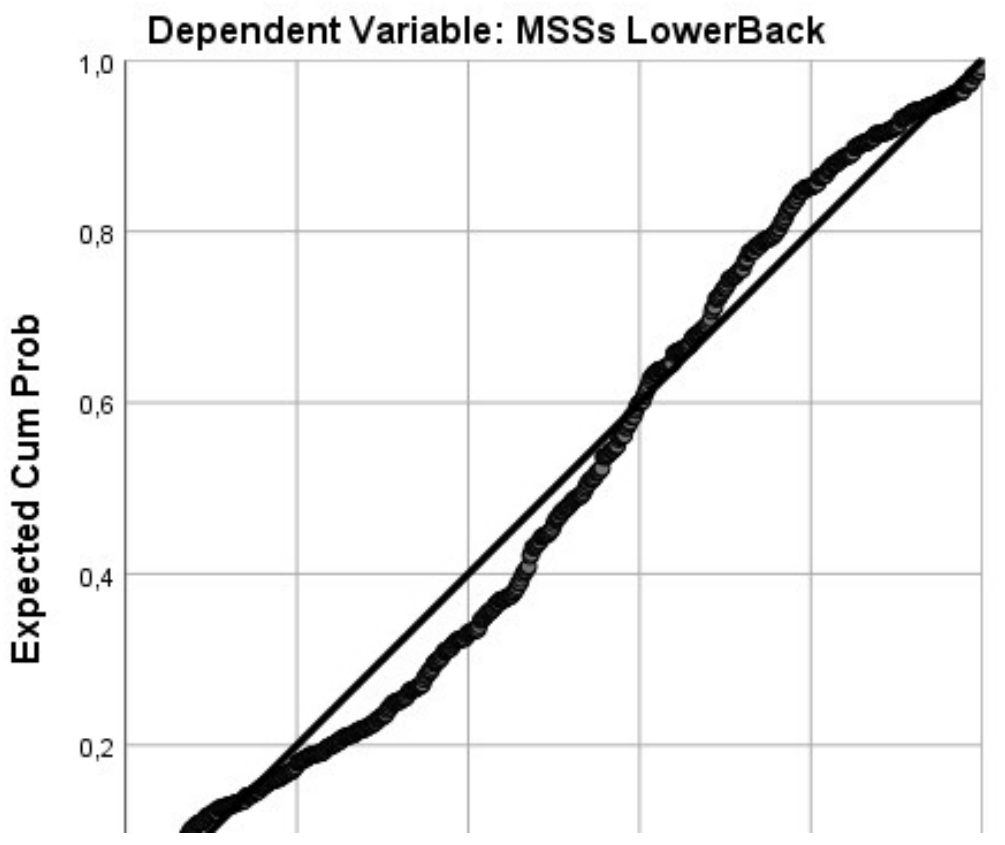


Partial Regression Plot

Dependent Variable: MSSs LowerBack

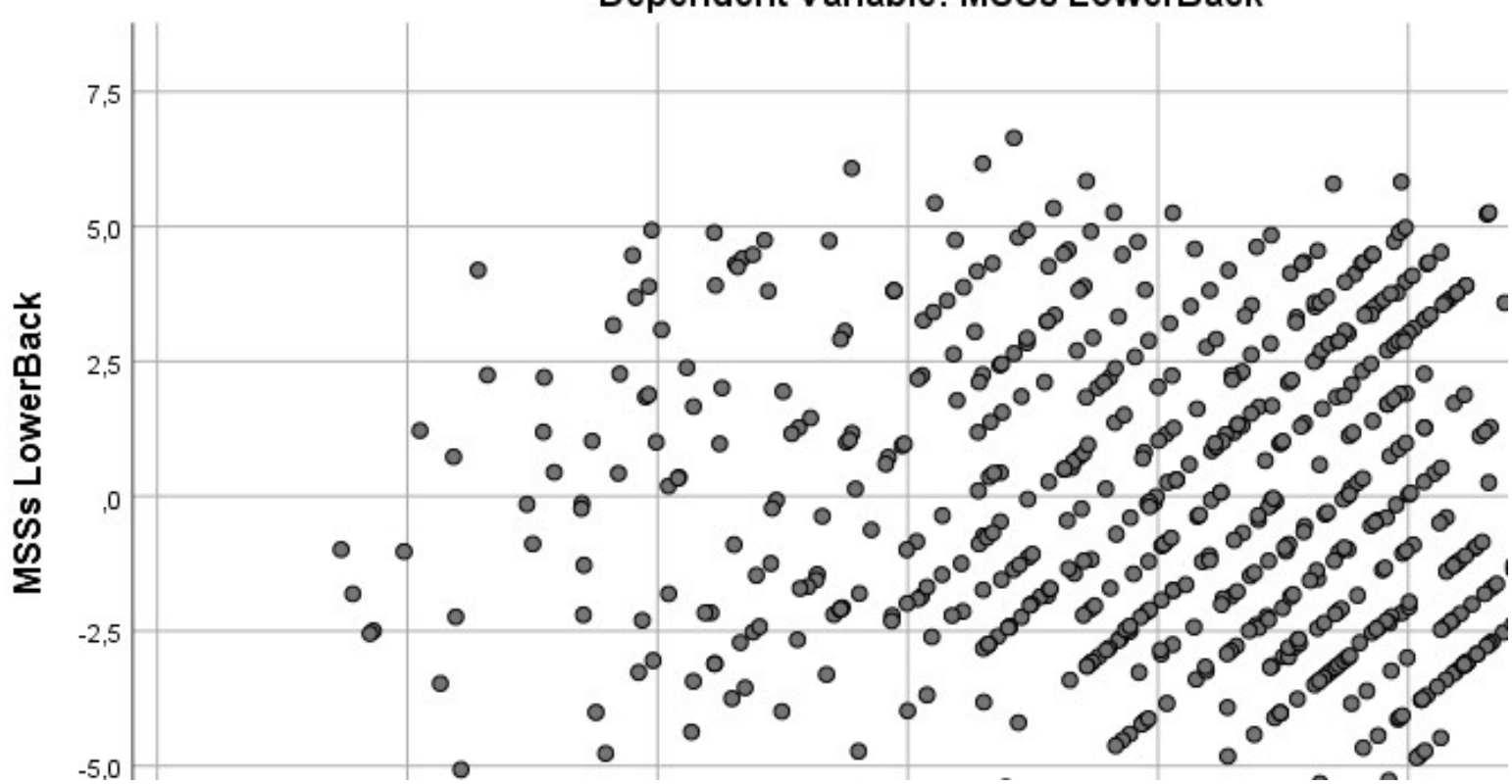

Partial Regression Plot

Dependent Variable: MSSs LowerBack

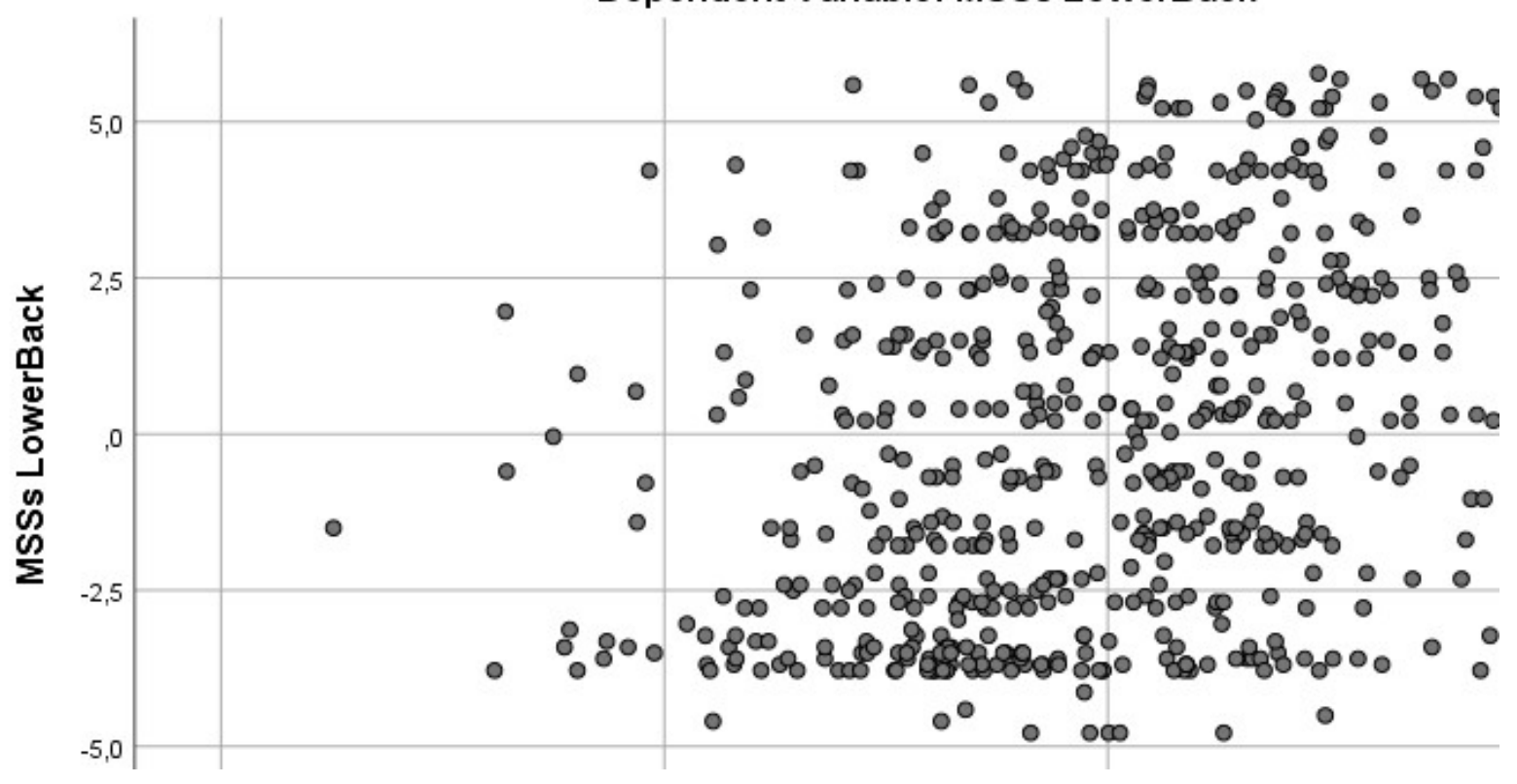




\section{Men's Group}

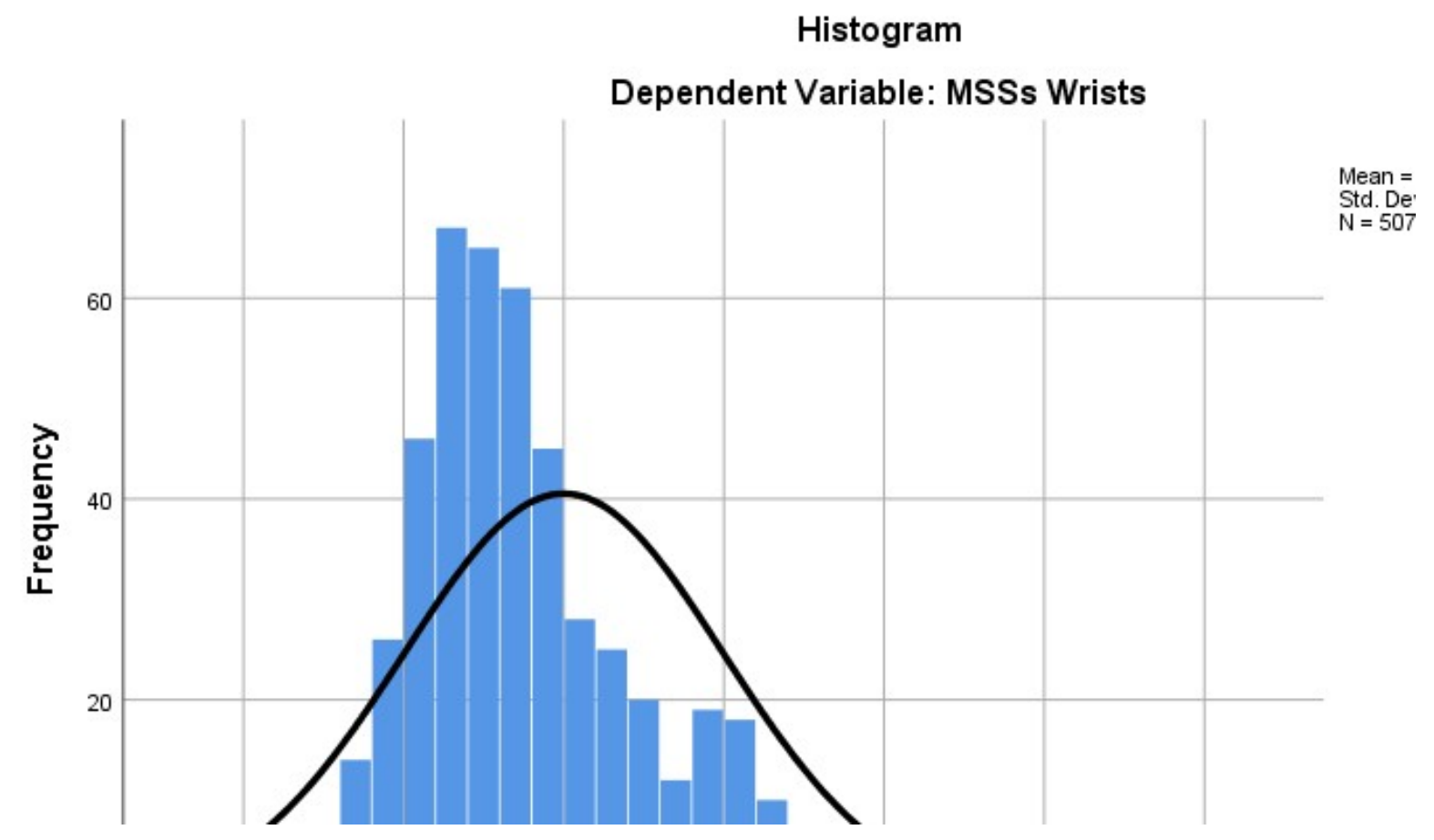

Normal P-P Plot of Regression Standardized Residual

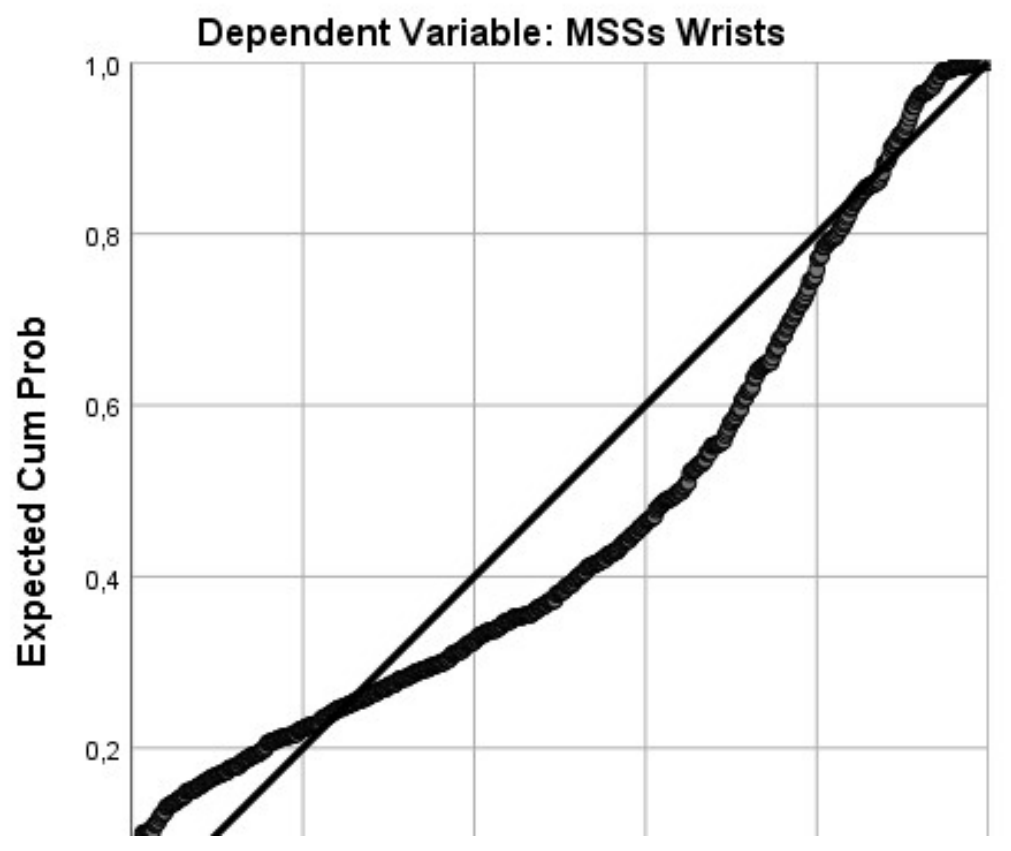


Partial Regression Plot

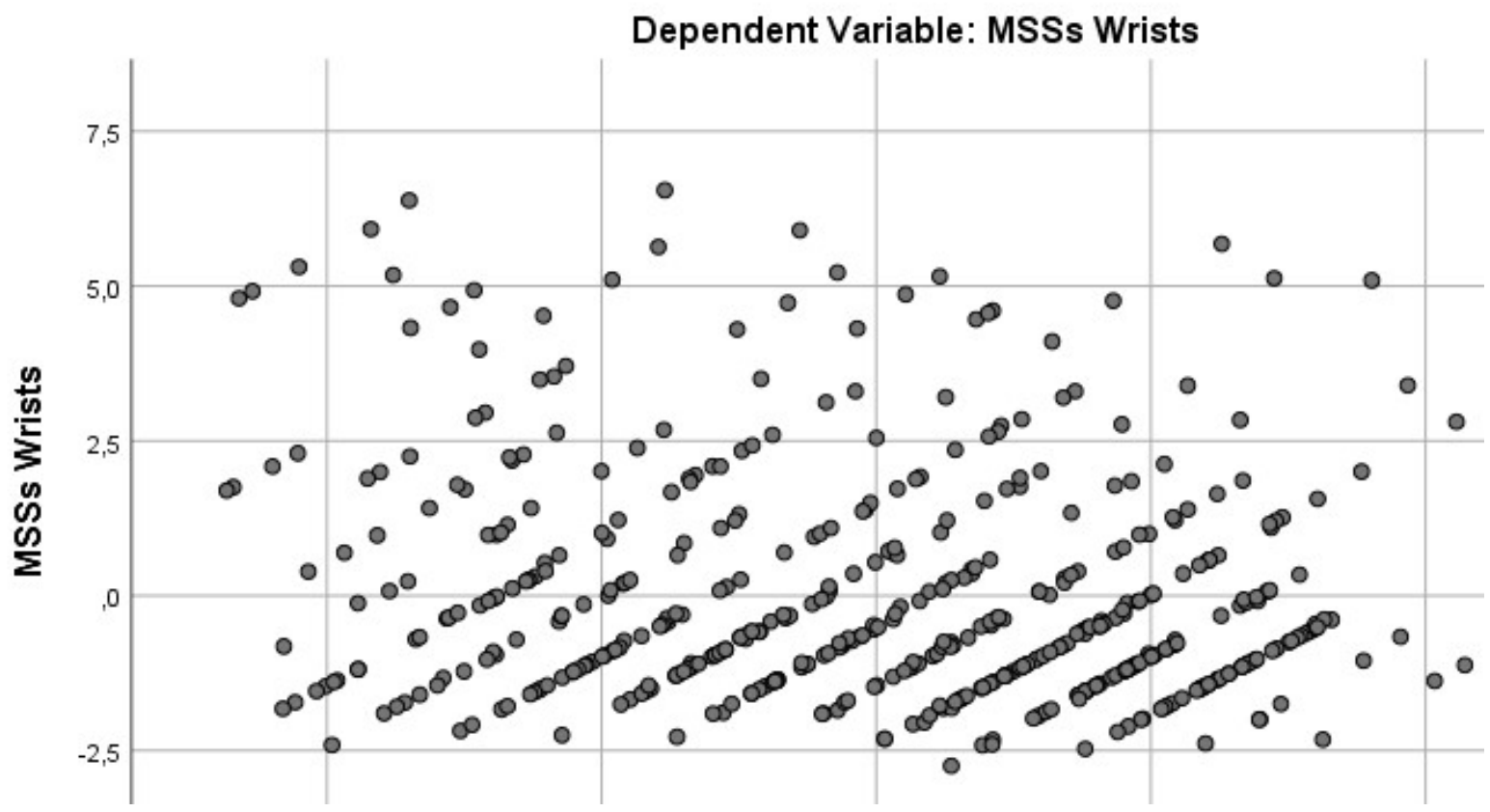

Partial Regression Plot

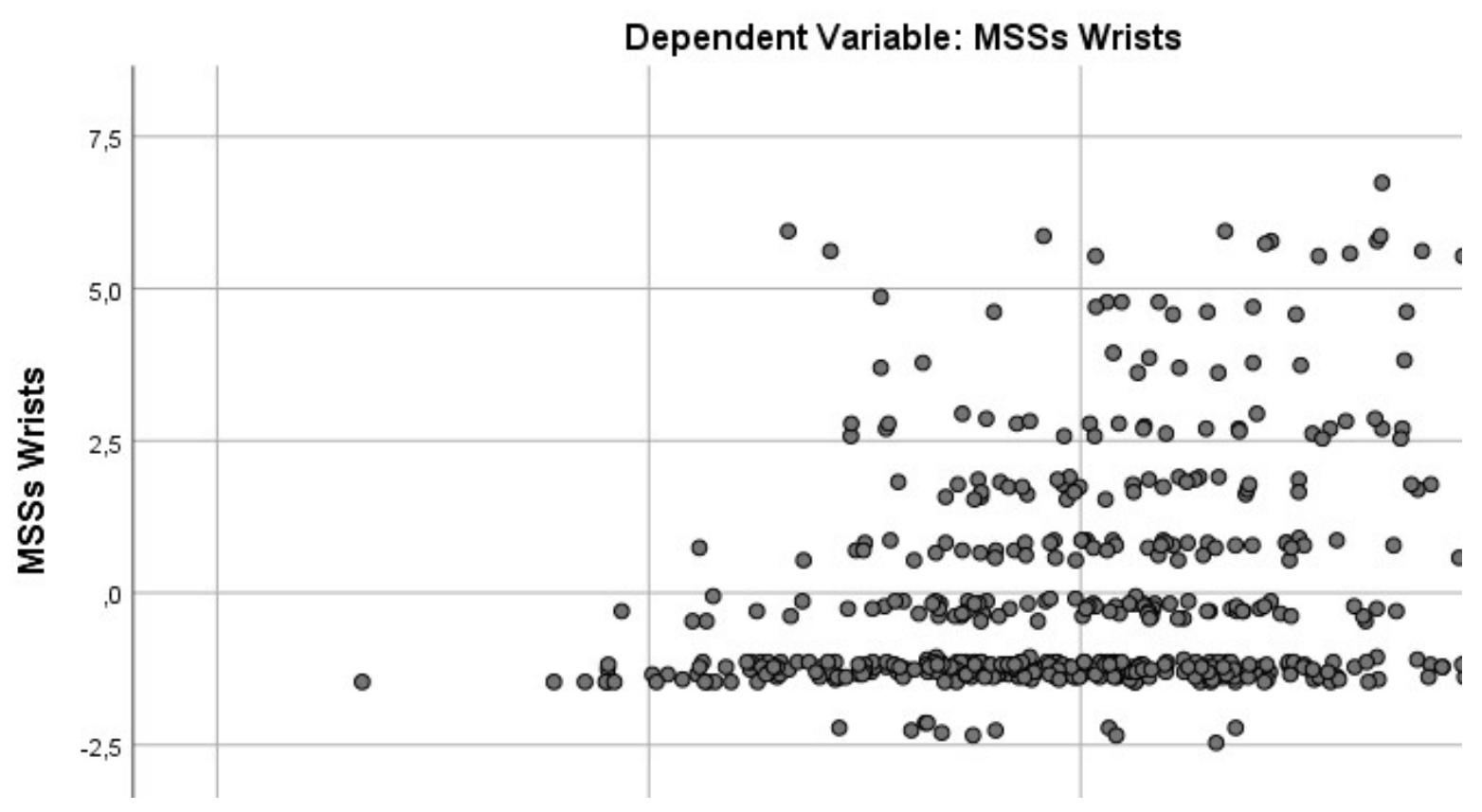




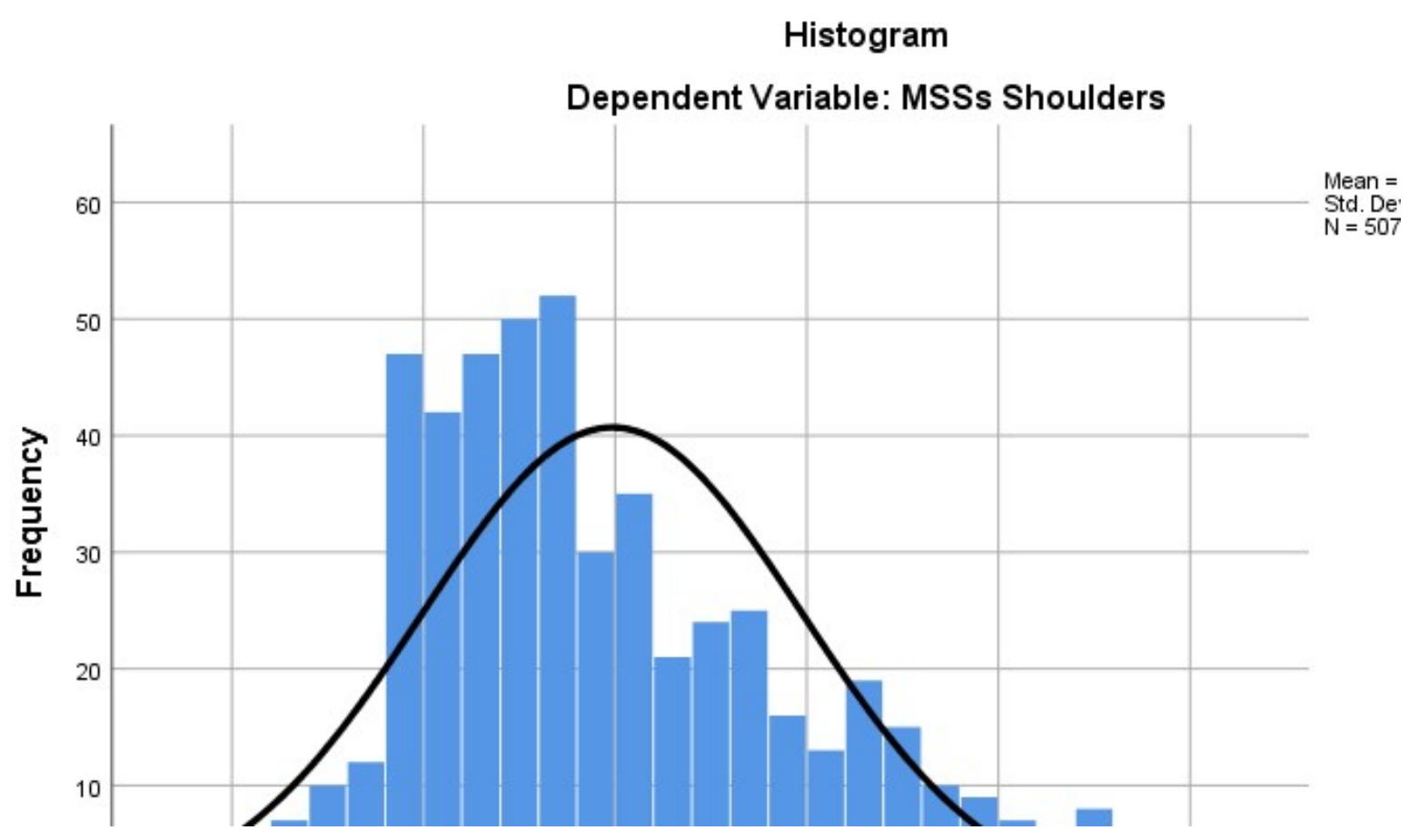

Normal P-P Plot of Regression Standardized Residual

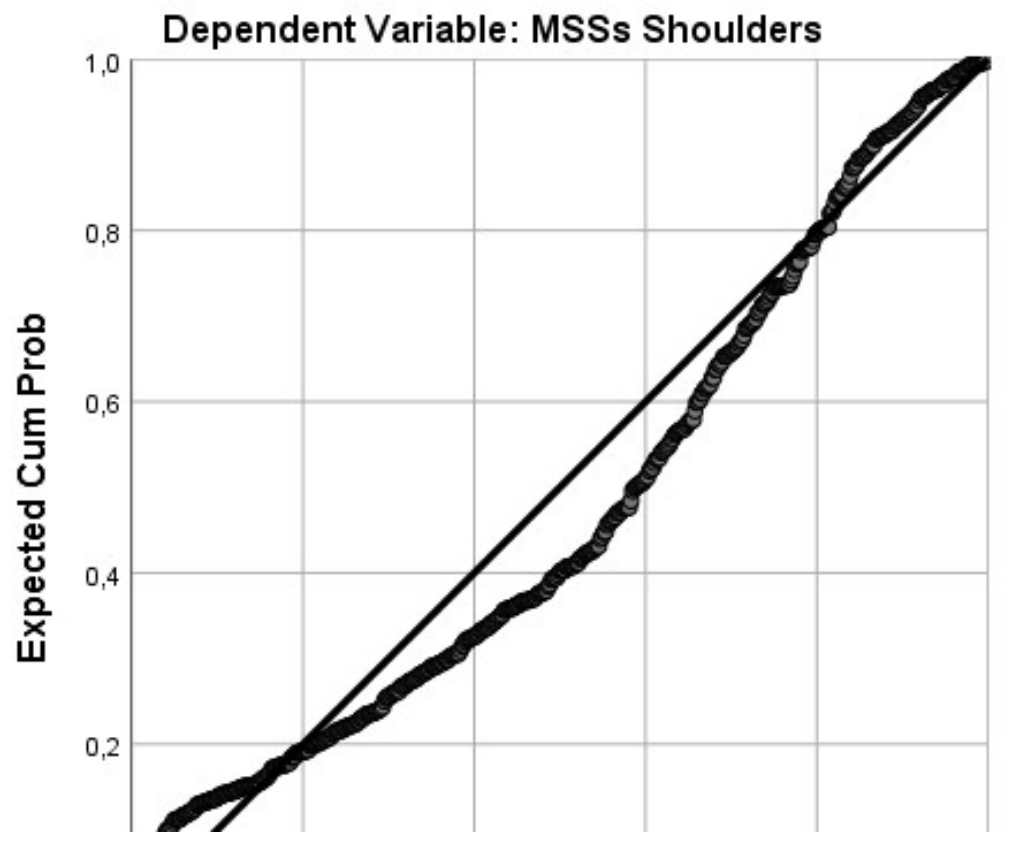


Partial Regression Plot

Dependent Variable: MSSs Shoulders

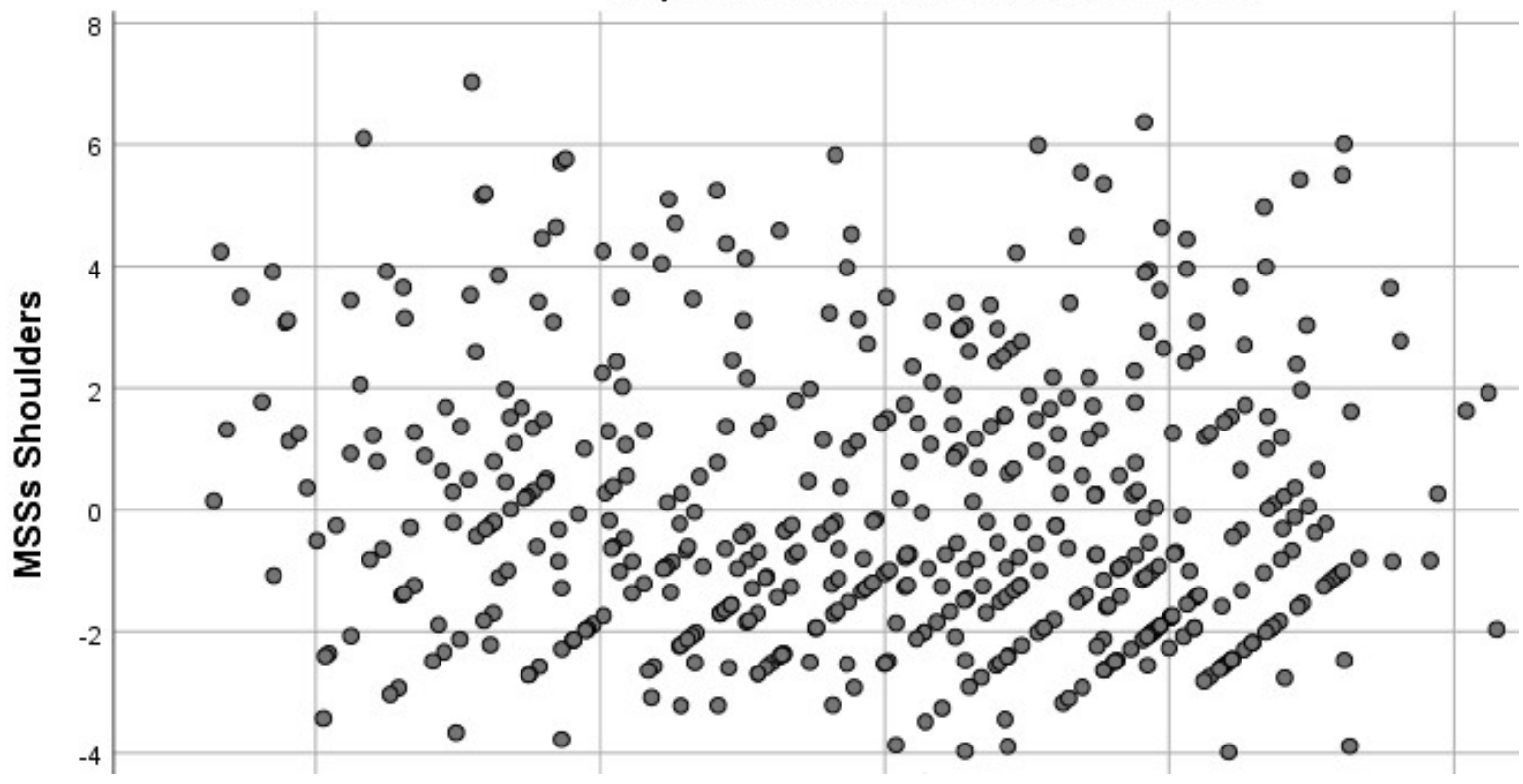

Partial Regression Plot

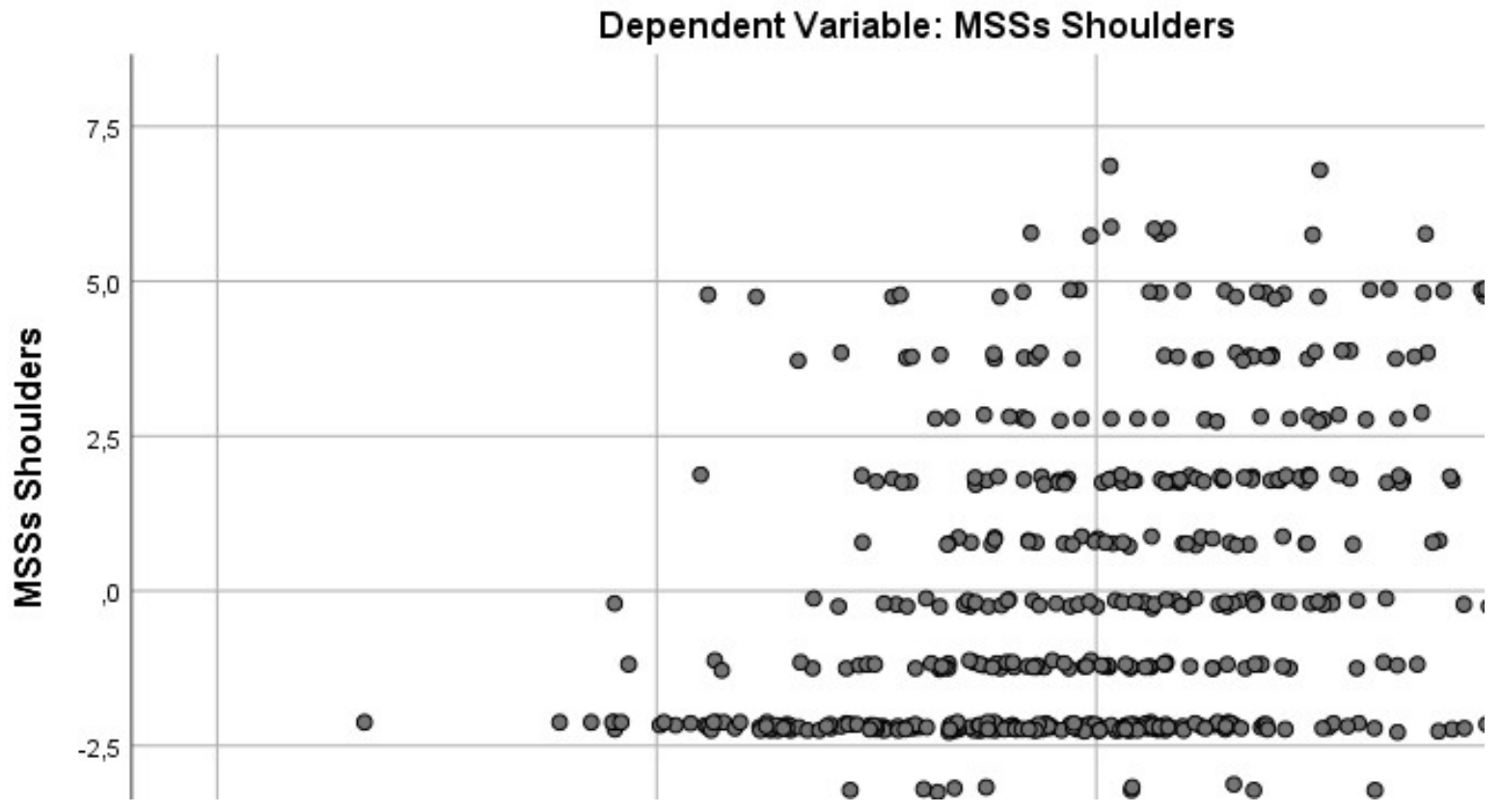




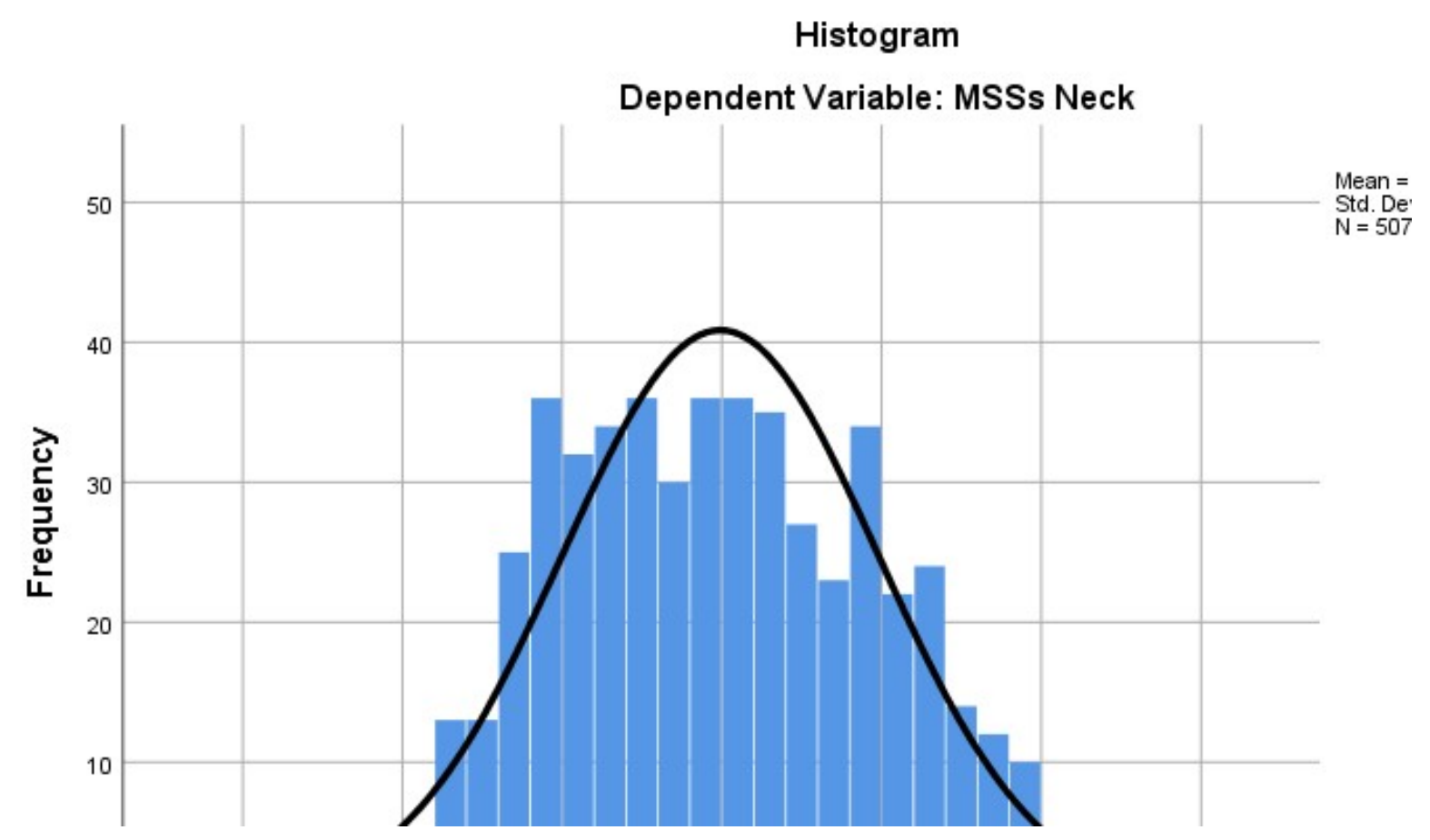

Normal P-P Plot of Regression Standardized Residual

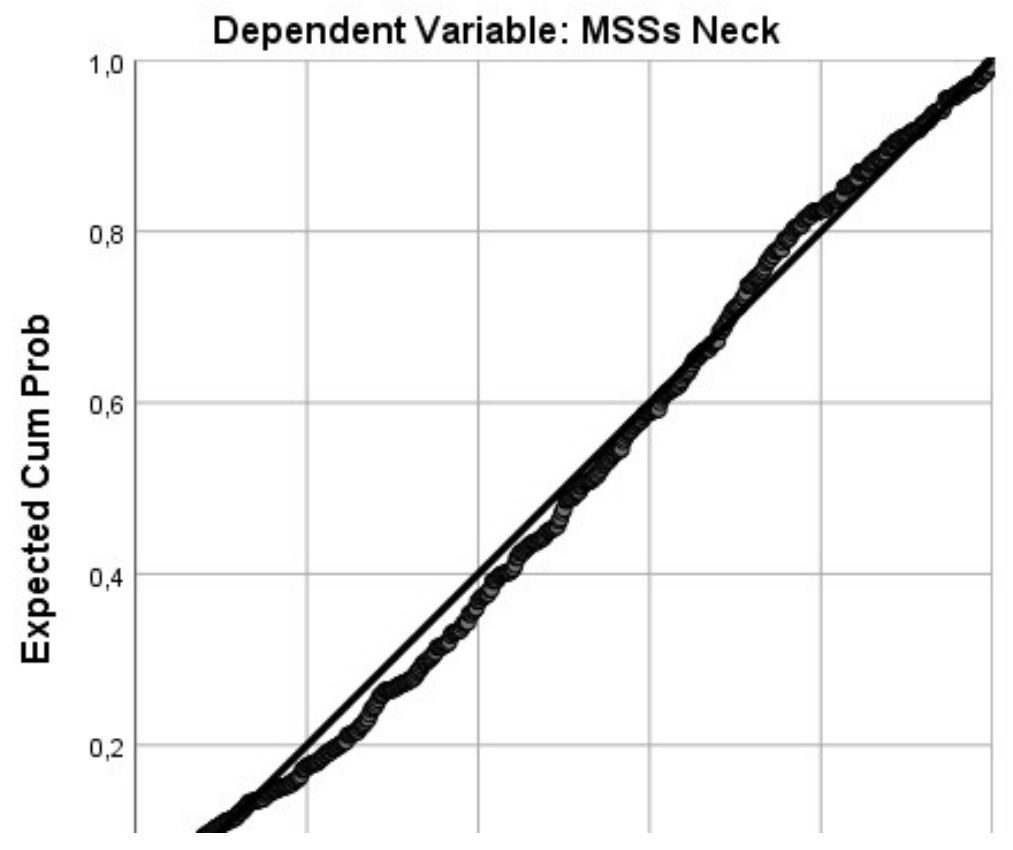


Partial Regression Plot

Dependent Variable: MSSs Neck

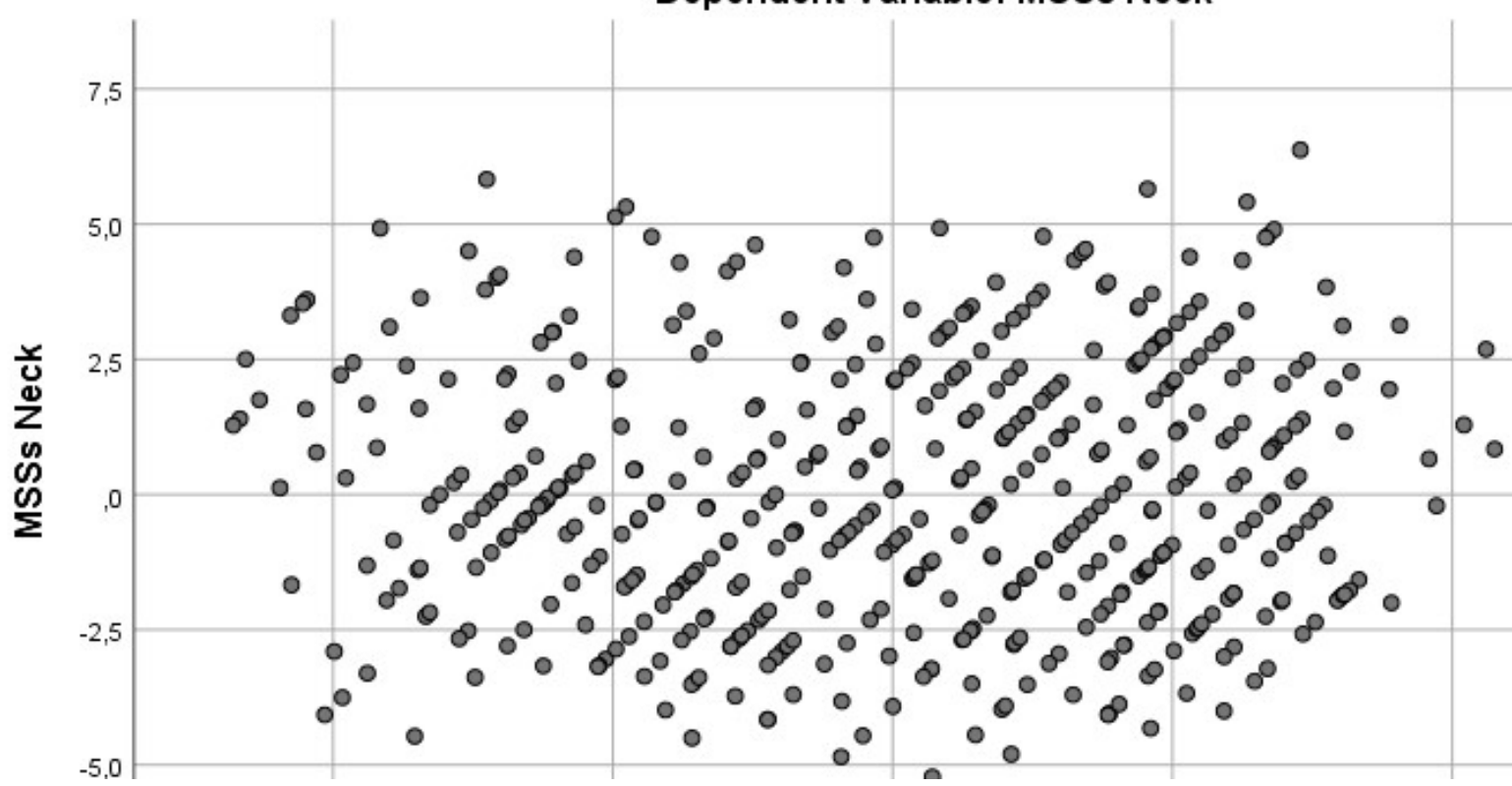

Partial Regression Plot

Dependent Variable: MSSs Neck

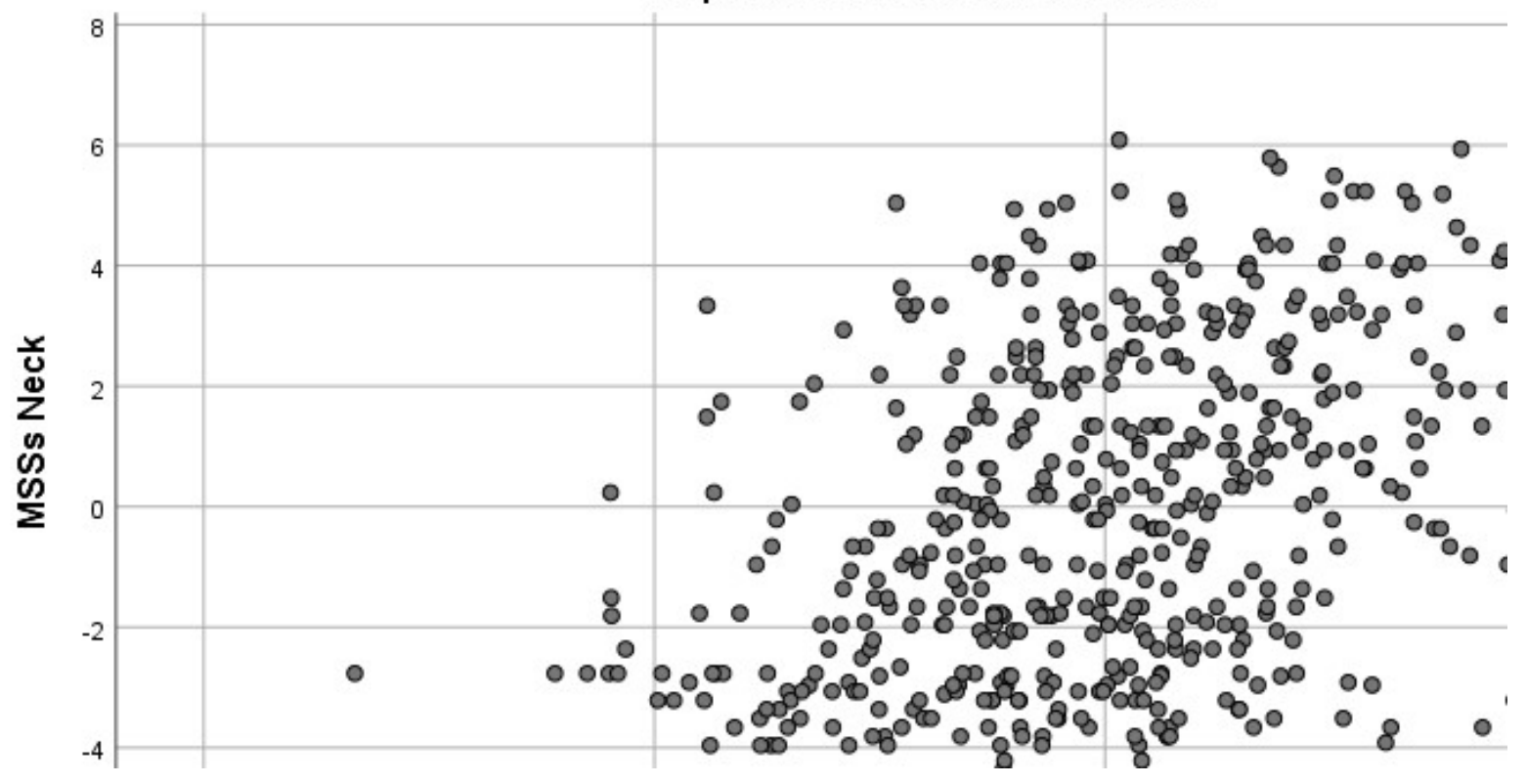




\section{Histogram}

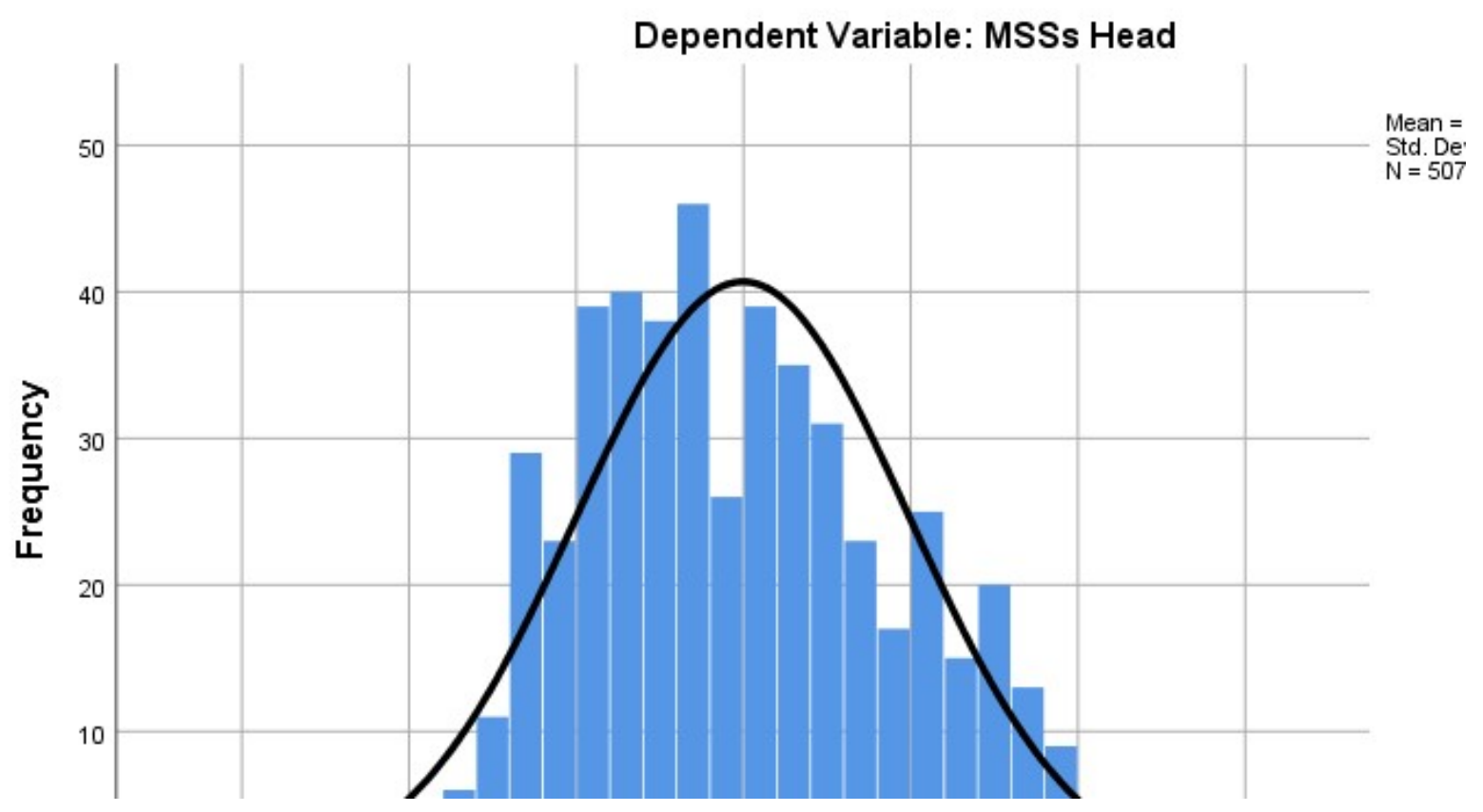

Normal P-P Plot of Regression Standardized Residual

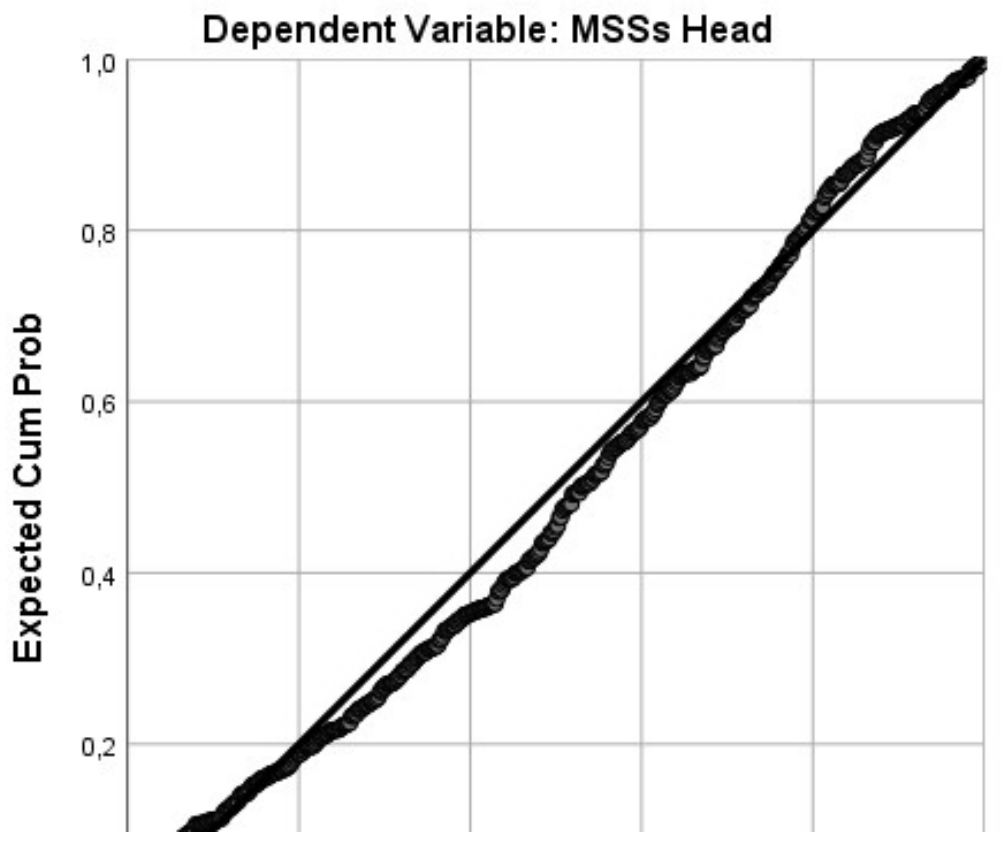


Partial Regression Plot

Dependent Variable: MSSs Head

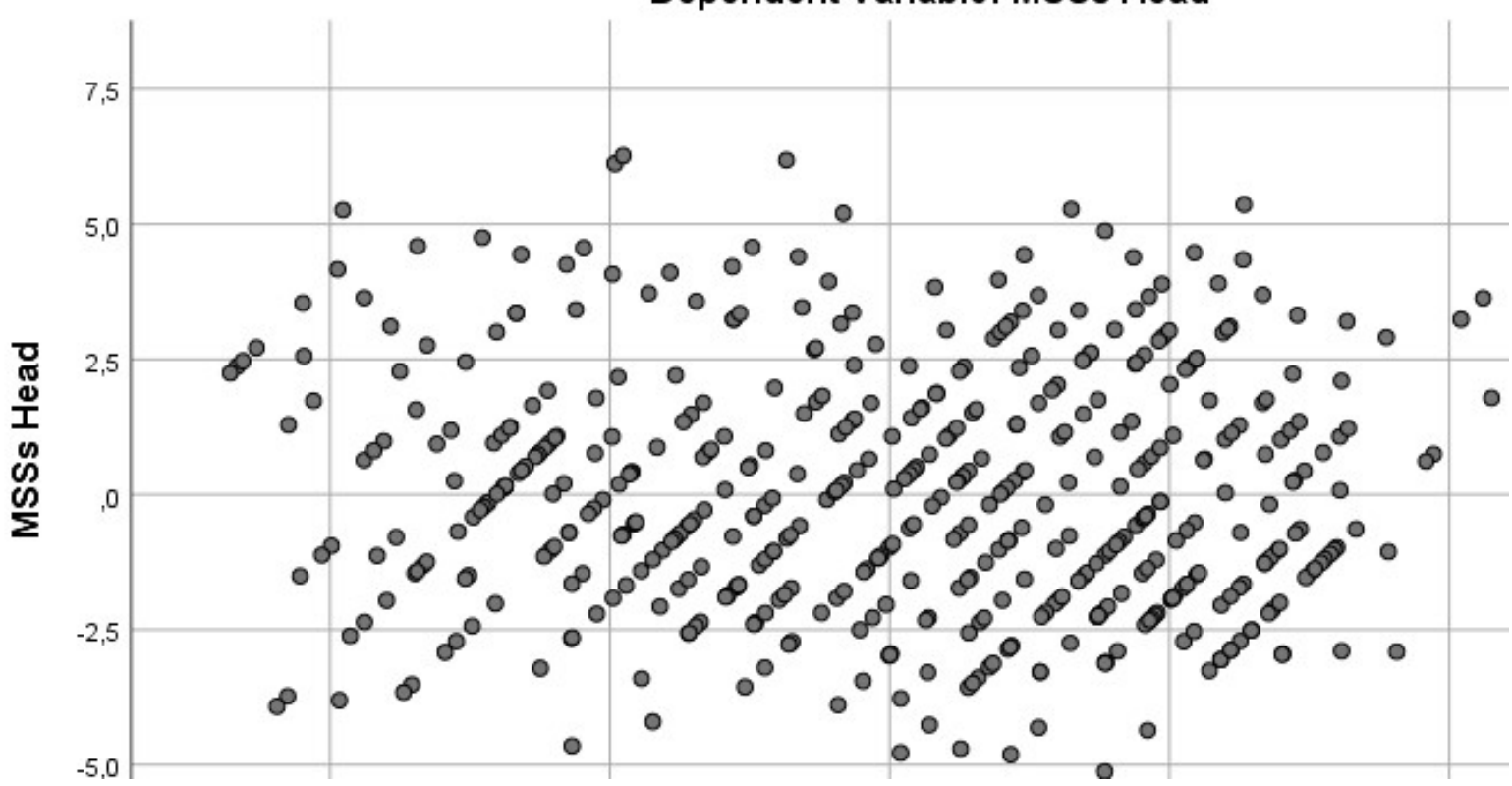

Partial Regression Plot

Dependent Variable: MSSs Head

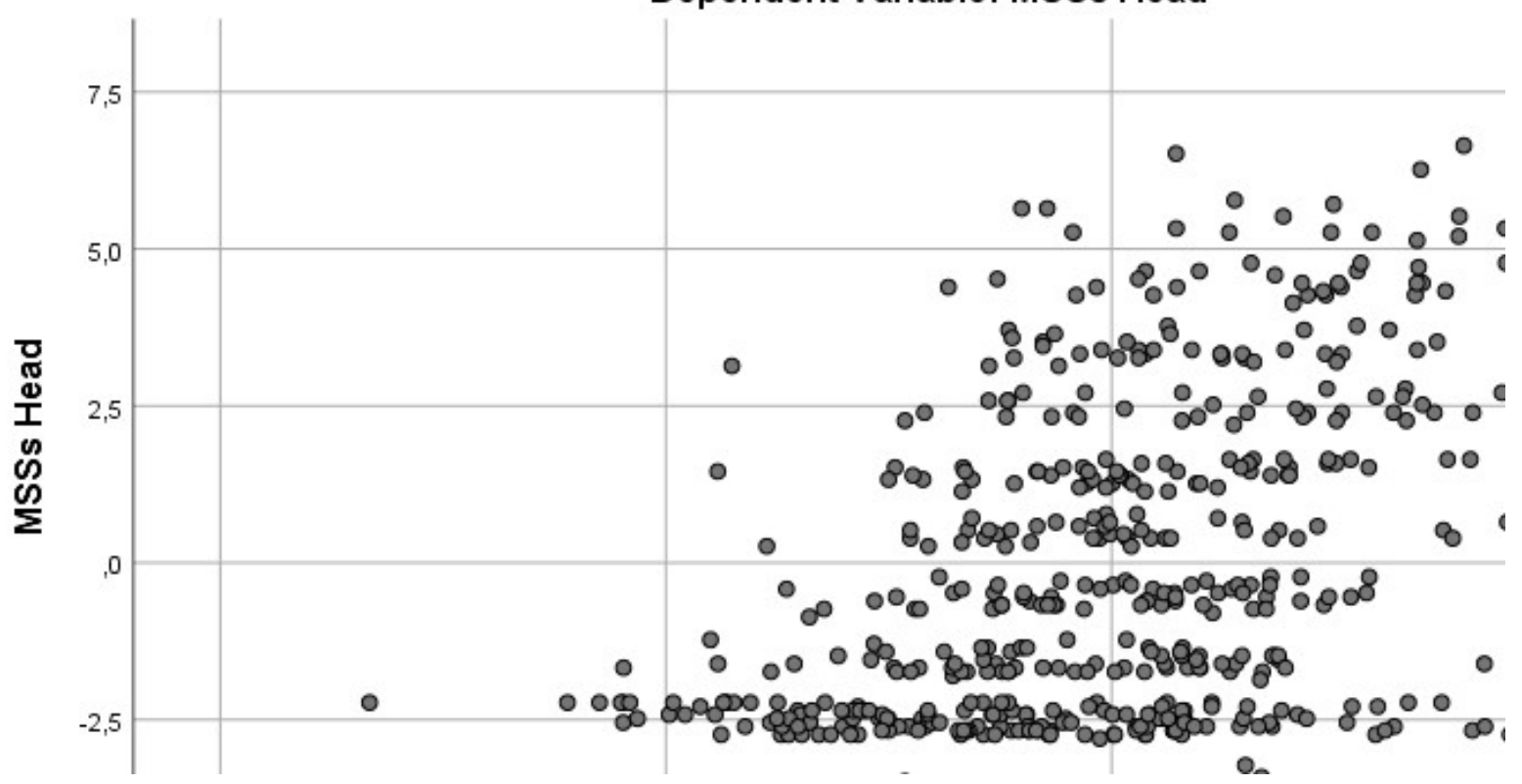




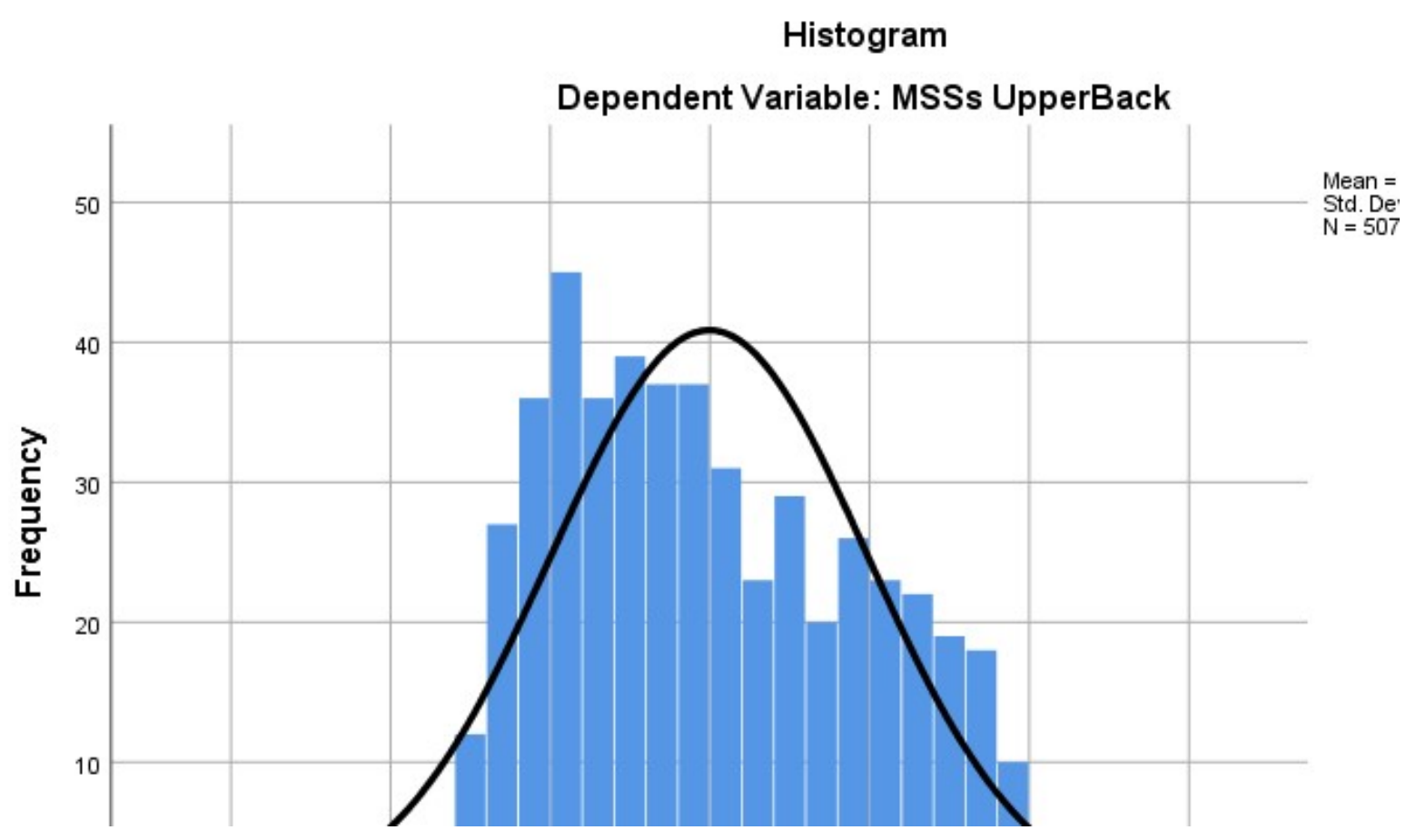

Normal P-P Plot of Regression Standardized Residual

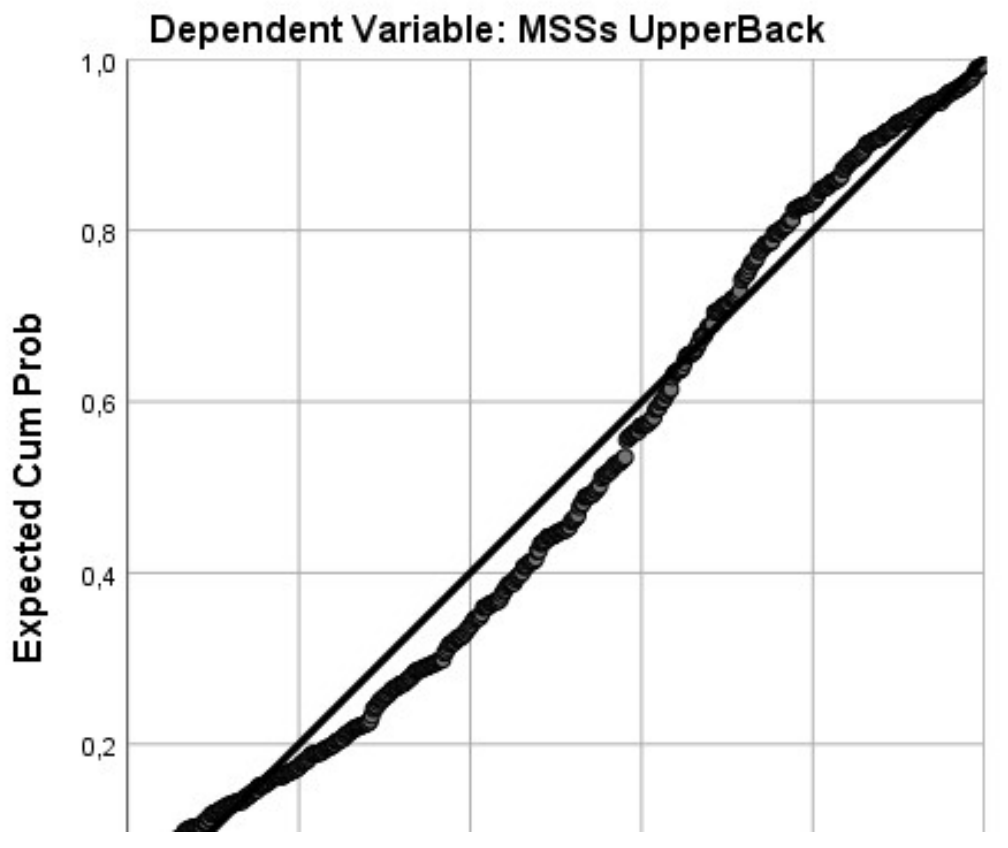


Partial Regression Plot

Dependent Variable: MSSs UpperBack

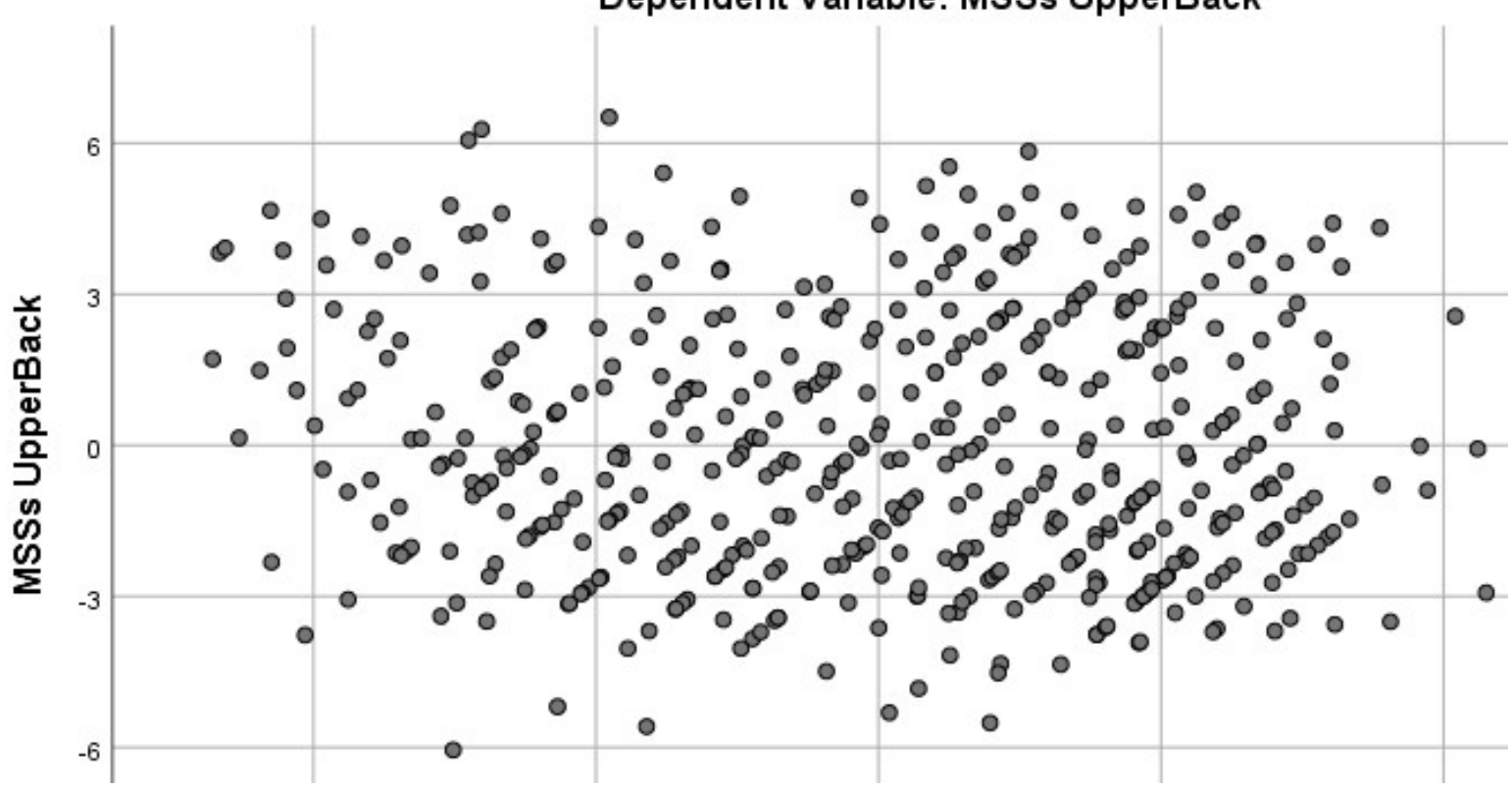

Partial Regression Plot

Dependent Variable: MSSs UpperBack

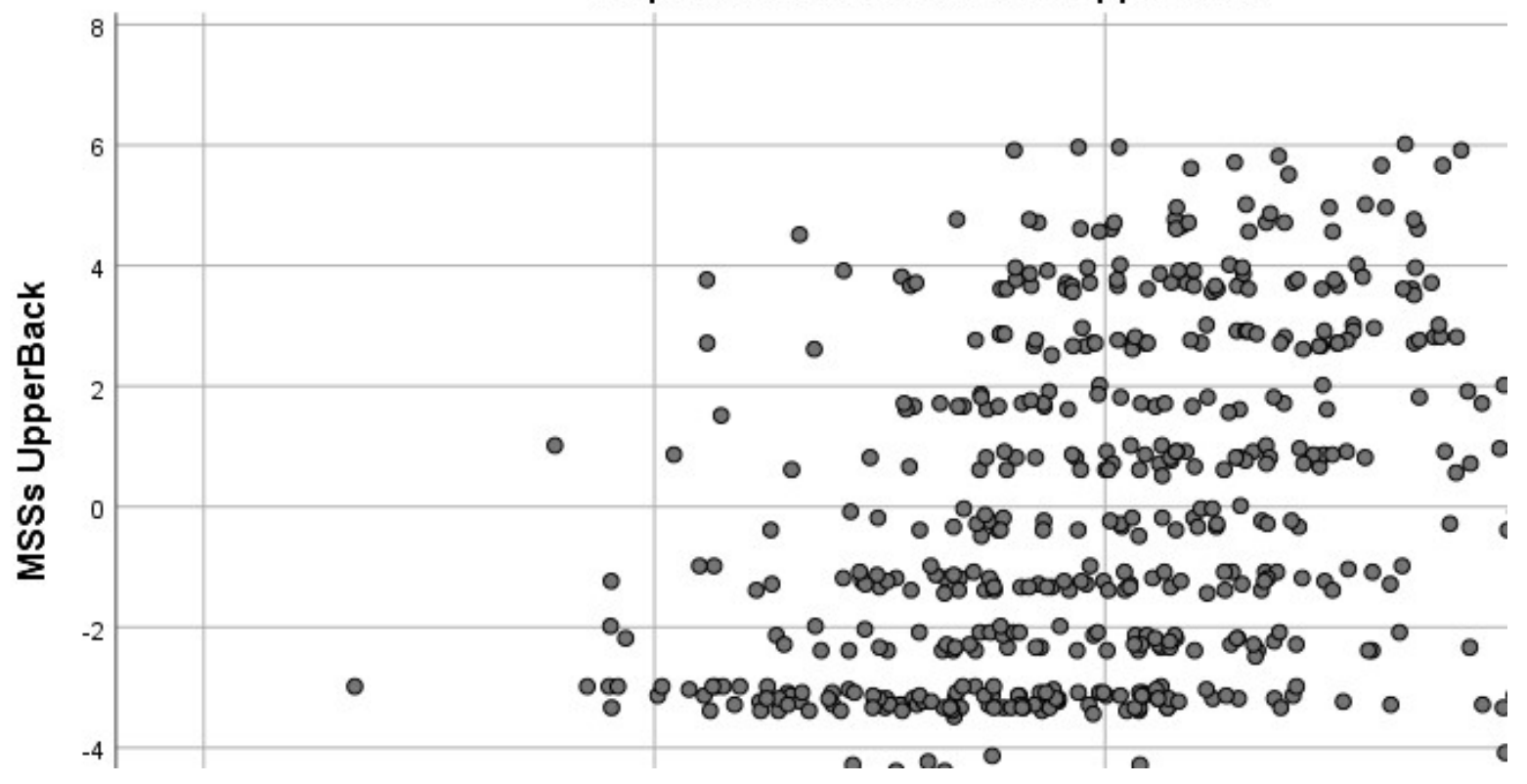




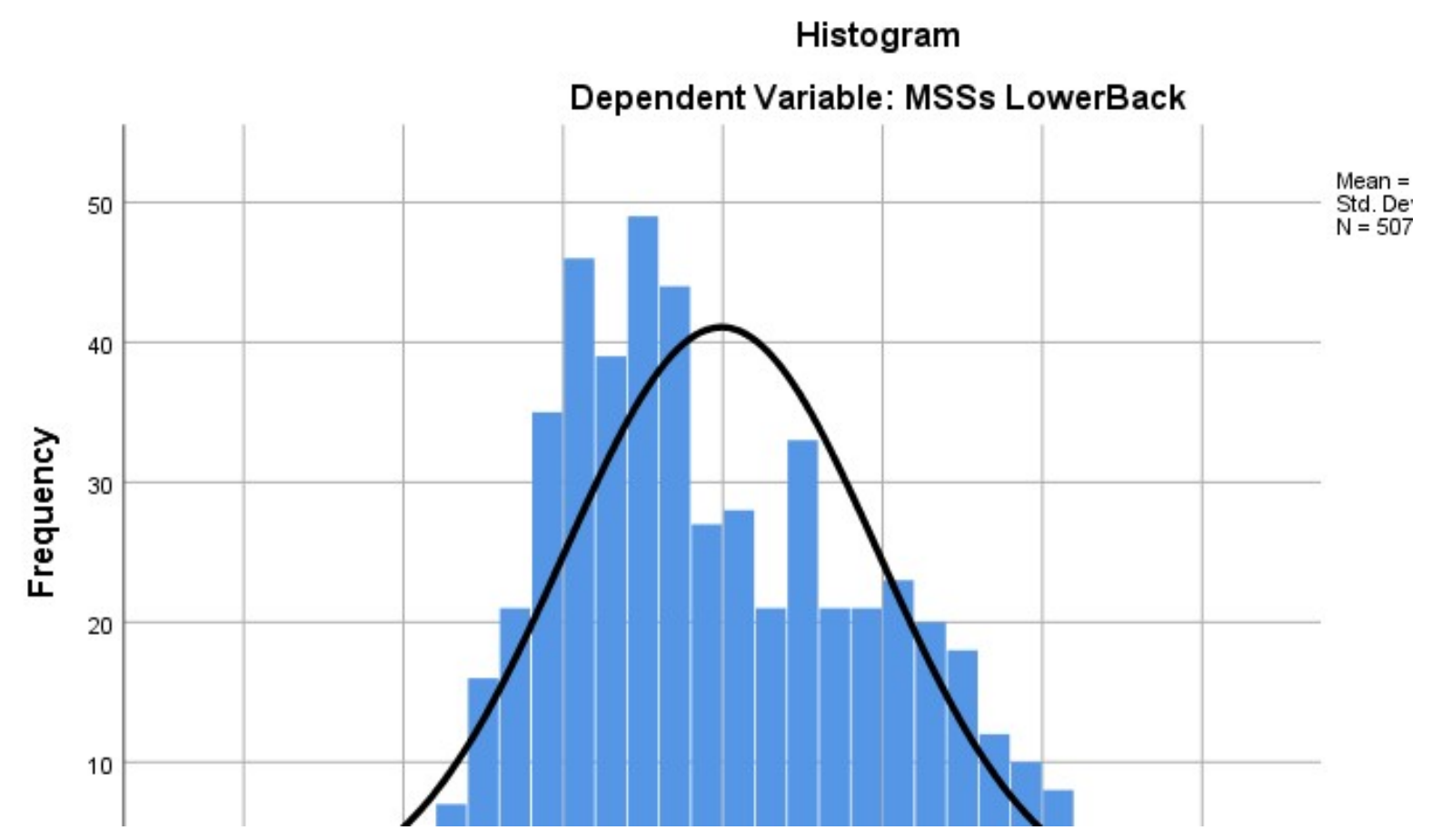

Normal P-P Plot of Regression Standardized Residual

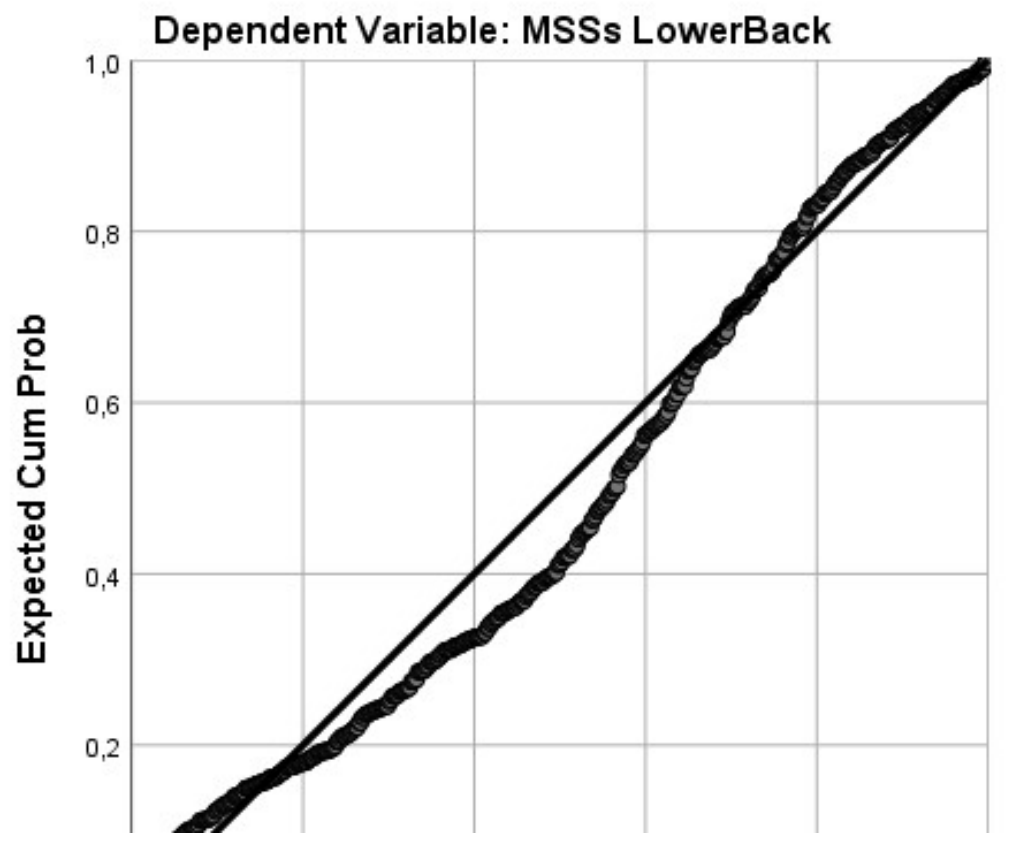


Partial Regression Plot

Dependent Variable: MSSs LowerBack

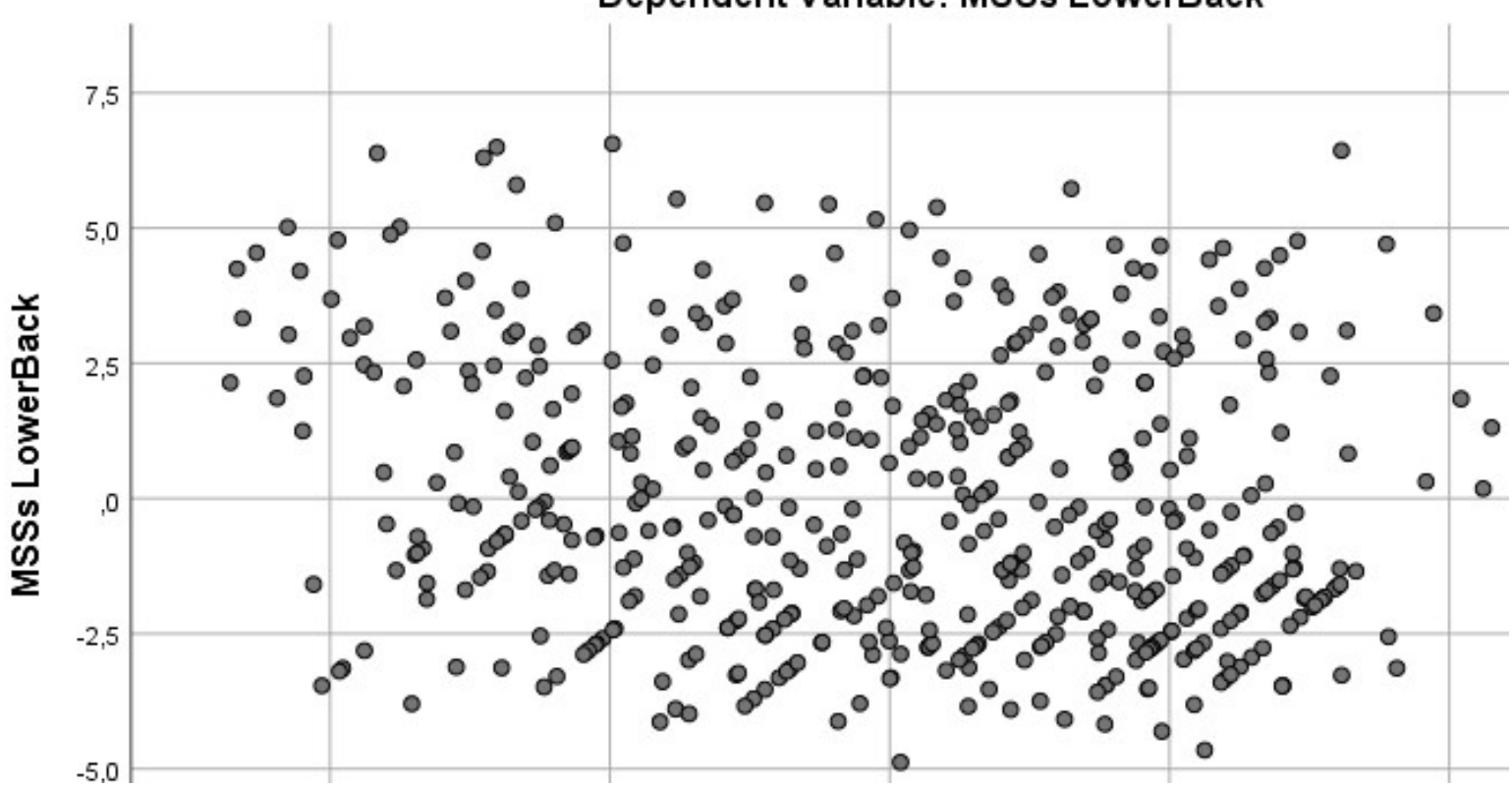

Partial Regression Plot

Dependent Variable: MSSs LowerBack

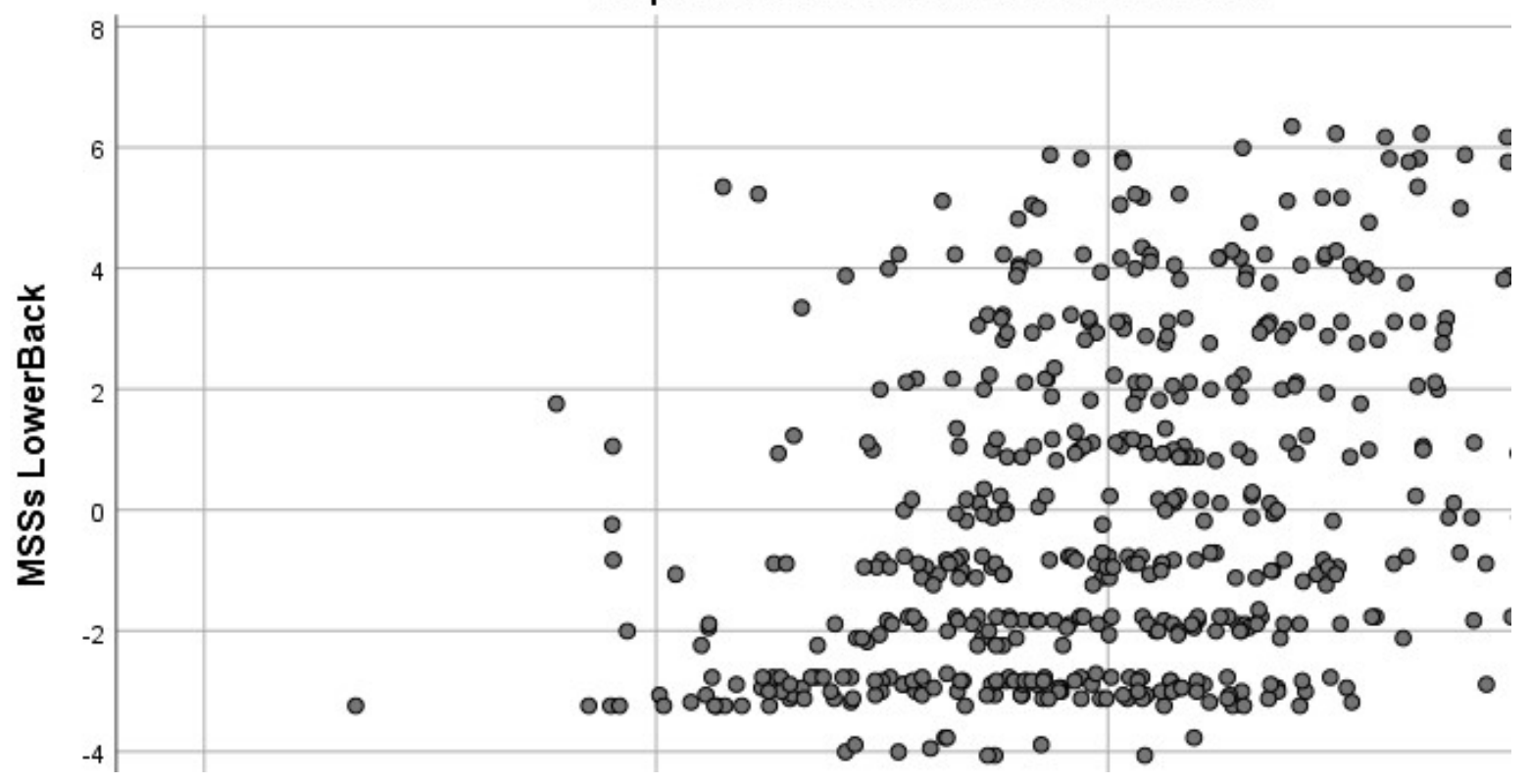

